\title{
Evaluation of the informed consent process for male circumcision scale-up in Swaziland
}

\author{
Barbara Friedland \\ Population Council \\ Louis Apicella \\ Population Council \\ Katie D. Schenk \\ Population Council \\ Meredith Sheehy \\ Population Council \\ Paul C. Hewett \\ Population Council
}

Follow this and additional works at: https://knowledgecommons.popcouncil.org/departments_sbsr-hiv

Part of the Community Health and Preventive Medicine Commons, Demography, Population, and Ecology Commons, Health Services Research Commons, Immune System Diseases Commons, International Public Health Commons, Medicine and Health Commons, Public Health Education and Promotion Commons, and the Virus Diseases Commons How does access to this work benefit you? Let us know!

\section{Recommended Citation}

Friedland, Barbara, Louis Apicella, Katie D. Schenk, Meredith Sheehy, and Paul C. Hewett. 2011.

"Evaluation of the informed consent process for male circumcision scale-up in Swaziland," Population Council Research and Evaluation of Male Circumcision Scale-up Report. New York: Population Council. 


\section{Evaluation of the Informed Consent Process for Male Circumcision Scale-up in Swaziland}

Population Council Research and Evaluation of Male Circumcision Scale-up-Report \#3

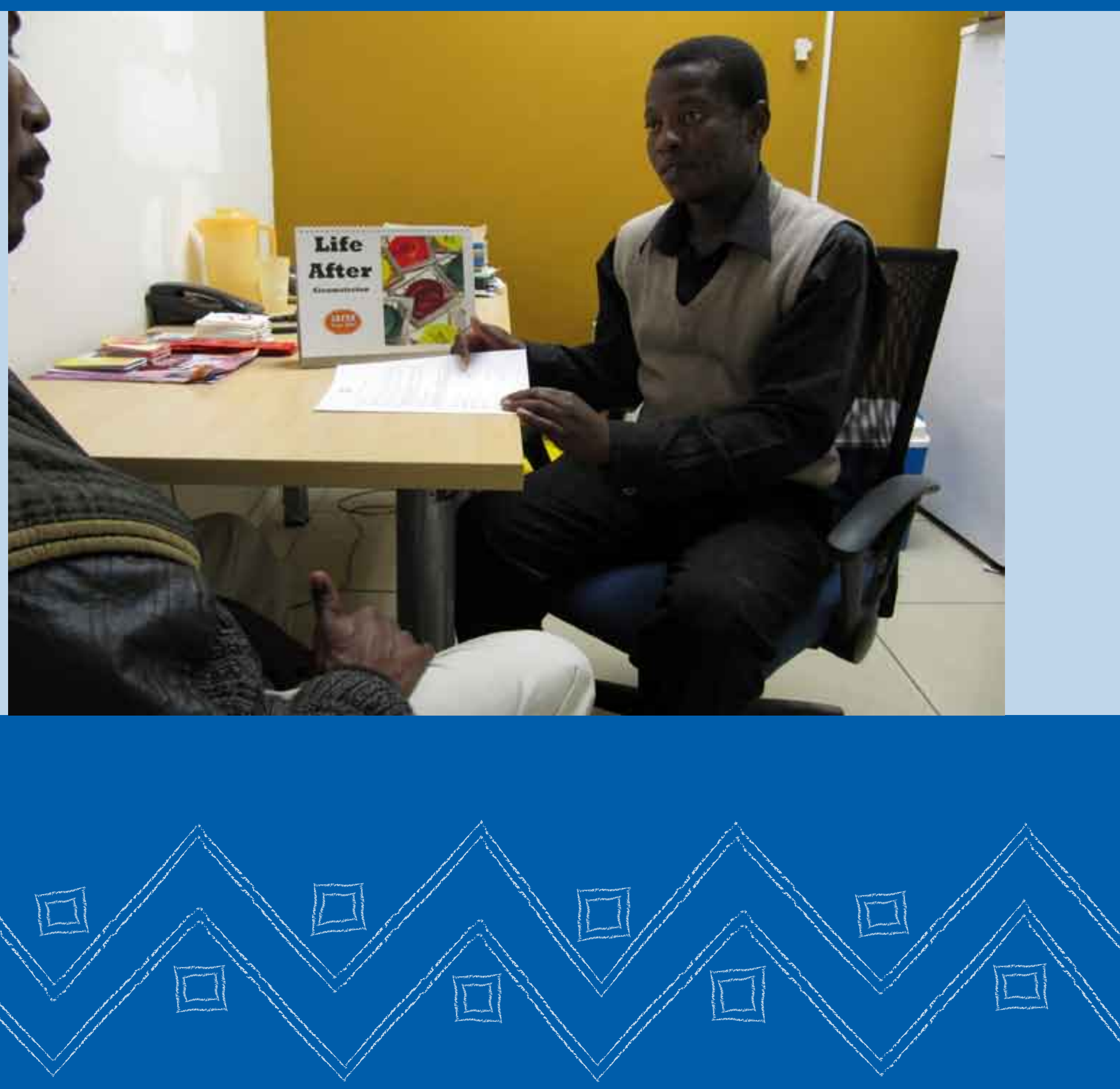





\title{
Evaluation of the Informed Consent Process for Male Circumcision Scale-up in Swaziland
}

\author{
Barbara Friedland, Lou Apicella, Katie Schenk, \\ Meredith Sheehy, and Paul C. Hewett
}

Population Council Research and Evaluation of Male Circumcision Scale-up-Report \#3

August 2011 


\section{ACKNOWLEDGMENTS}

Principal investigators for this study were Barbara Friedland and Louis Apicella (Population Council, New York and Swaziland). Co-investigators were Katie Schenk and Paul C. Hewett (Population Council, Washington, DC; and Lusaka, Zambia). Meredith Sheehy (Population Council, New York) and Mandla Malaza (Population Services International, Swaziland) were study coordinators. Alfred Adams (Population Council, Swaziland) managed field work. Interviewers were Bhekisisa Bulunga, Mdudzi Cele, Pheuduliwe Dlamini, Sizakele Khumalo, Sozabile Mabuzu, Linganiso Mayimbela, Khethuxolo Mngomezulu, Lomaguga Shabangu, and Mathokoza Sibandze. Paul C. Hewett directed the Population Council's MC research and evaluation program, and Naomi Rutenberg (Population Council, Washington, DC) served as Senior Technical Advisor.

The research team thanks Jessi Greene (PSI, Swaziland) and Steve Gesuale and Hayden Hawry (Society for Family Health, Zambia) for their support and active input into the study; as well as Marie Stopes International, Swaziland; Family Life Association (FLAS) of Swaziland; and Jhpiego, Baltimore, MD. Special thanks to the clinic staff who facilitated study implementation; and to Sharon Abbott, Maria Alevrontas, Max Gill, Nicole Haberland, Virginia Kallianes, Barbara Mensch, Barbara Miller, and Roman Zadorozhny (Population Council, New York); and Sherry Hutchinson (Population Council, Washington, DC) for their contributions to the design and implementation of the study, and development of this report; and to Robert Heidel (Population Council, New York) for copyediting.

The research team is especially grateful to the clients, and to the parents or guardians of adolescents, who generously gave their time or allowed their children to participate.

This study was conducted under a sub-grant from Population Services International (PSI) through the Male Circumcision Partnership, which is sponsored by PSI with support from The Bill \& Melinda Gates Foundation.

\footnotetext{
1 Population Council The Population Council conducts research worldwide to improve policies, programs, and products in three areas: HIV and AIDS; poverty, gender, and youth; and reproductive health. www.popcouncil.org
}

\footnotetext{
Suggested citation: Friedland, Barbara, Lou Apicella, Katie Schenk, Meredith Sheehy, and Paul C. Hewett. 2011. "Evaluation of the informed consent process for male circumcision scale-up in Swaziland," Population Council Research and Evaluation of Male Circumcision Scale-up_Report \#3. New York: Population Council.
}

Published August 2011. Copyright (C2011 The Population Council, Inc.

This document may be reproduced in whole or in part without permission of the Population Council provided full source citation is given and the reproduction is not for commercial purposes. 


\section{TABLE OF CONTENTS}

ABBREVIATIONS AND ACRONYMS iv

$\begin{array}{ll}\text { EXECUTIVE SUMMARY } & 1\end{array}$

INTRODUCTION 4

HIV and Male Circumcision in Swaziland 4

Informed Consent 5

Ethical Issues Related to Minors 5

$\begin{array}{ll}\text { Study Objectives } & 6\end{array}$

METHODS $\quad 6$

Study Instrument Development $\quad 6$

$\begin{array}{ll}\text { Interviewer Training } & 6\end{array}$

$\begin{array}{ll}\text { Recruitment } & 7\end{array}$

Quantitative Methods $\quad 7$

Qualitative Methods 9

Ethical Considerations 9

$\begin{array}{lr}\text { Limitations } & 10\end{array}$

$\begin{array}{ll}\text { RESULTS } & 11\end{array}$

BACKGROUND DEMOGRAPHICS 11

$\begin{array}{ll}\text { Quantitative Comprehension Assessment } & 11\end{array}$

$\begin{array}{lr}\text { Semi-structured Interviews with Male Circumcision Clients } & 12\end{array}$

DECISIONMAKING PROCESS

$\begin{array}{ll}\text { Information Sources } & 12\end{array}$

$\begin{array}{ll}\text { Motivating Factors } & 13\end{array}$

$\begin{array}{ll}\text { Decision Comfort } & 13\end{array}$

$\begin{array}{ll}\text { COUNSELING } & 15\end{array}$

$\begin{array}{ll}\text { Type of Counseling Received } & 15\end{array}$

Impressions of Counseling from Semi-structured Interview Respondents $\quad 17$

$\begin{array}{lr}\text { Presentation of Risks and Benefits } & 18\end{array}$

Comfort and Rapport $\quad 19$

Group versus One-on-One Counseling 19 
$\begin{array}{ll}\text { Results of Quantitative Comprehension Assessment } & 20\end{array}$

Concepts Explored in Semi-structured Interviews 22

$\begin{array}{ll}\text { INFORMED CONSENT } & 30\end{array}$

Differences between Informed Consent Forms by Clinic Site 30

Perceptions of Consent Form and Process among Adult Clients 30

Perceptions of Consent Form and Process among Adolescents 32

PROCEDURE AND RECOVERY 33

Preparation for Procedure $\quad 33$

Anesthesia 34

Surgery $\quad 34$

Recovery 34

$\begin{array}{ll}\text { Experience versus Expectation } & 35\end{array}$

HEALING $\quad 35$

Preparation for Healing $\quad 36$

$\begin{array}{ll}\text { Post-procedure Abstinence } & 37\end{array}$

Care during the Healing Process

$\begin{array}{ll}\text { Experience versus Expectation } & 37\end{array}$

Adverse Events: Hypothetical and Actual 38

Post-Surgical Follow-up Visits 39

CLIENT INPUT ON SERVICE DELIVERY 39

Outreach 40

$\begin{array}{ll}\text { Clinic Capacity } & 40\end{array}$

$\begin{array}{lr}\text { Counseling } & 40\end{array}$

$\begin{array}{ll}\text { Anesthesia } & 41\end{array}$

$\begin{array}{ll}\text { Surgery and Recovery } & 41\end{array}$

$\begin{array}{ll}\text { Female Service Providers } & 41\end{array}$

Decisionmaking Process $\quad 42$

Counseling $\quad 42$

Comprehension $\quad 43$

Informed Consent 44

Procedure and Recovery $\quad 44$

Healing $\quad 45$

Expand Outreach Messages $\quad 45$

Enhance Counseling Process 46

Improve Aspects of the Informed Consent Process 49 
Appendix A. Study Objectives, Research Questions, and Methods $\quad 50$

Appendix B. Recruitment Targets and Enrollment

Appendix C. Characteristics of Clients Who Participated in Quantitative Comprehension Assessment

Appendix D. Decisionmaking Process

53

Appendix E. Quantitative Comprehension Assessment: Additional Results

REFERENCES 


\section{ABBREVIATIONS AND ACRONYMS}

\begin{tabular}{|c|c|}
\hline $\mathrm{ABC}$ & abstinence, be faithful, use condoms \\
\hline $\mathrm{AE}$ & adverse event \\
\hline AES & advanced encryption standard \\
\hline AIDS & Acquired Immune Deficiency Syndrome \\
\hline AOR & adjusted odds ratio \\
\hline CD4 & cluster of differentiation 4 cell (CD4+ T-lymphocyte) \\
\hline CI & confidence interval \\
\hline CT & HIV counseling and testing \\
\hline EDC & electronic data capture \\
\hline FGD & focus group discussion \\
\hline FLAS & Family Life Association of Swaziland \\
\hline HIV & Human Immunodeficiency Virus \\
\hline HPV & human papillomavirus \\
\hline IC & informed consent \\
\hline IEC & information, education, and communication \\
\hline IPC & interpersonal communication \\
\hline IRB & institutional review board \\
\hline Jhpiego & Johns Hopkins International Health NGO (not an acronym) \\
\hline $\mathrm{MC}$ & male circumcision \\
\hline MC Partnership & Male Circumcision Partnership \\
\hline MIS & management information system(s) \\
\hline $\mathrm{MOH}$ & Ministry of Health \\
\hline MSI & Marie Stopes International \\
\hline $\mathrm{NGO}$ & non-governmental organization \\
\hline PC & Population Council \\
\hline PEPFAR & President's Emergency Plan for AIDS Relief \\
\hline PI & principal investigator \\
\hline PSI & Population Services International \\
\hline SEC & Scientific and Ethics Committee (of Swaziland) \\
\hline SMS & short message service \\
\hline SSI & semi-structured interview \\
\hline STD & sexually transmitted disease \\
\hline STI & sexually transmitted infection \\
\hline UNAIDS & The Joint United Nations Programme on HIV/AIDS \\
\hline WHO & World Health Organization \\
\hline
\end{tabular}




\section{EXECUTIVE SUMMARY}

An evaluation of the informed consent (IC) process for male circumcision (MC) was conducted through the Male Circumcision Partnership (MC Partnership) for Swaziland, led by Population Services International (PSI), in partnership with Jhpiego, Marie Stopes International (MSI), and the Population Council (PC). The MC Partnership was established with the support of the Bill and Melinda Gates Foundation and the President's Emergency Plan for AIDS Relief (PEPFAR) to work closely with the Ministry of Health, via the MC Task Force in Swaziland, to advance the National MC Policy and Strategy to scale up MC services in the public, private, and NGO sectors. Ongoing scale-up of MC services is now supported directly by PEPFAR.

\section{Study Objectives}

Between May and August 2010, the Population Council conducted an evaluation of the IC process for MC in Swaziland to meet three study objectives:

1. Assess MC clients' comprehension of key concepts in the MC IC process;

2. Explore how adults and adolescents who have recently undergone circumcision believe their experiences compared to their expectations based on MC counseling; and

3. Make recommendations for improving the MC IC process.

\section{Methods}

Quantitative and qualitative methods were used to evaluate the IC process among adult (18 years and older) and adolescent (13-17 years old) MC clients. A ten-question, true/false comprehension test was administered to $\mathrm{MC}$ clients after counseling and prior to undergoing surgery. Statistical tests were used to test the hypothesis that 90 percent of clients could pass the comprehension test, scoring 80 percent or better (answering at least eight out of ten questions correctly). Scores were also compared between several subgroups: adults vs. adolescents; and clients attending static vs. outreach, urban vs. rural, and MC Partnership vs. non-partnership sites.

Qualitative data collection involved semi-structured interviews (SSIs), conducted with MC clients (adults and adolescents) one week post-surgery, to assess comprehension of key MC concepts and to ascertain how clients believe their experiences compared to their expectations based on MC counseling.

\section{Results}

Data were included from 953 clients who participated in the quantitative comprehension assessment (756 adults, 197 adolescents) and 30 clients who participated in SSIs (16 adults, 14 adolescents). Most clients were young (19.6 years, on average for the qualitative cohort; 23.4 years, on average for the quantitative cohort) and single, with high levels of literacy and education. 


\section{Decisionmaking process}

Adults most frequently learned about MC from friends and the media, while adolescents heard about it primarily through school (mainly during clinic-initiated "back-to-school" campaigns) and family members. Clients participating in SSIs sought MC primarily for disease prevention, although HIV was not always mentioned specifically. The majority of adults who participated in the comprehension assessment reported being somewhat or very comfortable with the decision to undergo MC, compared to less than half of the adolescents; and, although the majority of adults reported feeling that they had been given the opportunity to change their minds, only a minority of adolescents, most of whom had been recruited during a mass campaign, felt this way. Results from SSIs indicated that clients (adults and adolescents) may have been comfortable with the decision to undergo MC, yet may have had lingering fears and concerns about the actual procedure.

\section{Counseling}

The majority of clients participating in both the quantitative and qualitative parts of the study had received the recommended counseling package, including group and one-on-one $\mathrm{MC}$ counseling, plus HIV counseling and testing (CT). Clients interviewed one week post-MC reported that, in general, counselors had done a good job providing information about MC that helped to reaffirm their decision to undergo the surgery. Some clients, however, reflected that, in retrospect, they had been better prepared for what to expect during the healing process than during the surgery itself; others felt that benefits of $\mathrm{MC}$ had been emphasized more than potential risks. Clients felt comfortable with counselors, even if they had complaints about specific aspects of counseling (e.g., inadequate information or not having the opportunity to meet with a counselor individually). Clients reported benefits of the various types of counseling: CT enabled them to know their HIV status before continuing with MC; group sessions allowed people to learn from others and feel a sense of camaraderie; and one-on-one counseling offered the chance to ask personal questions.

\section{Comprehension}

Results of the quantitative assessment indicated excellent overall comprehension of key MC concepts: 93.4 percent of MC clients passed the true/false comprehension test (scoring 80 percent or better); however, there was a statistically significant difference $(\mathrm{p}<0.001)$ in pass rates between adolescents and adults ( 85.3 percent vs. 95.5 percent); logistic regression also indicated that adults were more than three times as likely to pass the test compared to adolescents. The concept of "risk" was problematic for both quantitative and qualitative participants. Most clients who participated in SSIs knew MC is not 100 percent effective against HIV infection; however, comments from some clients seemed to indicate they thought they were now at minimal rather than reduced risk of getting HIV. There was also a lack of awareness that MC does not protect female partners from HIV, except indirectly. Clients seemed to have a clearer understanding of wound care instructions and the need to continue safer sex practices.

\section{Informed consent}

All of the clients interviewed in SSIs indicated that they had chosen to undergo MC voluntarily, with many emphasizing that it had been their own choice, free from pressure or coercion. Clients were less clear about the meaning of their signature on the IC form; some clients (particularly those from FLAS clinics) thought signing the form freed the service providers of 
all liability, whereas other clients seemed to understand that they had signed a form agreeing to the procedure, but had not had time to read it or know what it was about. Interviews with adolescents indicated that consent procedures for minors are not uniformly implemented; some adolescents seemed to have signed the consent form for themselves, despite being under 18 years of age. Regardless of who signed the consent forms, all of the adolescents participating in SSIs had clearly chosen to undergo $\mathrm{MC}$, and in all except one case, the adolescent had been the one to initiate the process.

\section{Procedure, recovery, and healing}

Most clients interviewed in SSIs one week post-surgery reported having been surprised not to have experienced any pain during the actual cutting of the foreskin. Some clients felt they had not been well-prepared for the procedure, however, primarily because they had not expected multiple injections of anesthesia. Most clients felt that counseling had prepared them well for the healing process, and that following the instructions they had been given was yielding positive results. There was some confusion, however, about whether to wash the wound with soap, salt water, or water only. Clients seemed to have a good sense of what type of complications constituted an adverse event $(\mathrm{AE})$, and what to do should they experience an adverse reaction. Clients also understood that they needed to abstain from sexual activity for six weeks post-MC to promote wound healing; however, only two clients seemed to understand that initiating sexual activity too soon could also increase HIV risk.

\section{Recommendations}

Based on the evidence gathered through this study, the following recommendations are offered to improve the IC process for MC services.

\section{Expand outreach messages}

- Clarify information about partial protection; include message that $\mathrm{MC}$ does not protect women from HIV and is only partially protective against cervical cancer.

- Include practical information, such as expected duration of healing and time needed to take leave from work; to anticipate female service providers; and to be prepared to experience pain at some point before (injection), during, or after the MC procedure.

\section{Enhance counseling process}

- Renew efforts to ensure that clients receive both group and one-on-one MC counseling, even when clients opt out of CT.

- Consider development of a video to help improve understanding among clients with low levels of literacy.

- Improve adolescent comprehension by actively assessing their understanding rather than waiting for adolescents to ask questions; consider implementing a short quiz after counseling and before $\mathrm{MC}$ to ensure adolescents understand critical concepts.

- Increase emphasis to improve client understanding of key concepts, including:

- Partial protection applies to sexually transmitted infections (STIs) and cervical cancer, in addition to HIV; 
- MC leads to "lower" rather than "minimal" risk of HIV (and other STIs); include information about transmission via blood and vaginal secretions during sex, even after the foreskin has been removed;

- Lack of protective effect for female partners; and

- Use alternative language for "risk" of HIV/STI — such as "chance" or "possibility" - to distinguish between "risks" of MC surgery and "reduced risk" of HIV/STI.

\section{Improve aspects of the IC process}

- Revise FLAS IC form; liability clause may prevent clients from seeking care for AEs. ${ }^{1}$

- Provide adequate time for clients to read IC form and ask questions before surgery.

- Ensure consistent (and legally appropriate) implementation of adolescent consent procedures, which should be publicized during community outreach.

\section{INTRODUCTION}

Three randomized controlled trials demonstrated that male circumcision (MC) reduces the risk of HIV infection among heterosexual men by about 60 percent (Auvert et al. 2005; Bailey et al. 2007; Gray et al. 2007). Based on the results, a WHO/UNAIDS Technical Consultation recommended implementing MC in areas with high prevalence of HIV infection (WHO/ UNAIDS 2007). The largest impact on the AIDS epidemic is projected for southern Africa, where HIV prevalence is high and MC rates are low.

Health activists, human rights advocates, researchers, and policymakers, however, emphasize that MC is only partially effective against HIV and other sexually transmitted infections (STIs), and that HIV-positive men who are circumcised can still transmit HIV to a sexual partner. Therefore, UNAIDS and other organizations have emphasized promotion of MC in combination with other risk reduction methods, such as consistent condom use, partner reduction, delayed onset of sexual initiation, and HIV counseling and testing (CT). UNAIDS recommends a human rights-based approach to introducing and expanding $\mathrm{MC}$ services to ensure that procedures are carried out safely, with sound informed consent (IC), and without discrimination (UNAIDS 2008).

\section{HIV and Male Circumcision in Swaziland}

In Swaziland, HIV prevalence among men and women 15-49 years old is 19.7 percent and 31.1 percent, respectively, with prevalence rising sharply with age (CSO and Macro 2008). HIV in Swaziland is largely spread through heterosexual intercourse; polygamy and concurrent sexual partnerships are common and are also likely contributors to HIV prevalence. Although levels of HIV/AIDS awareness are relatively high, misconceptions persist about virus transmission and disease progression (CSO and Macro 2008).

In its "National Strategic Framework for HIV/AIDS in the Kingdom of Swaziland," the Government of Swaziland acknowledges that prevention is a key priority for the national response

${ }^{1}$ Based on the findings and preliminary recommendations from this study, the consent form being used by FLAS has already been revised to list surgical risks more specifically and to remove the clause about liability. 
to AIDS (Kingdom of Swaziland 2009). The Ministry of Health and Social Welfare has formally adopted MC as an HIV prevention intervention and created the MC Task Force to head this initiative.

The Male Circumcision Partnership (MC Partnership) for Swaziland was established with the support of the Bill and Melinda Gates Foundation and the President's Emergency Plan for AIDS Relief (PEPFAR) to work with the Swaziland government to scale up MC services. The MC Partnership is led by Population Services International (PSI), in partnership with Jhpiego, Marie Stopes International (MSI), and the Population Council. In 2009-2010, the MC Partnership worked closely with the Ministry of Health via the MC Task Force in Swaziland to advance the National MC Policy and Strategy to scale up MC services in the public, private, and NGO sectors, including a focus on increasing demand for MC services through social marketing and behavior change communication campaigns. Between early 2009 and the end of February 2011, approximately 22,000 MC procedures had been performed (PSI, personal communication). Ongoing scale-up of services is now being supported directly by PEPFAR.

\section{Informed Consent}

As the only biomedical intervention shown to reduce HIV transmission by up to 60 percent, there is great interest in introducing MC quickly and widely in areas of high HIV prevalence. Typically, areas of high HIV incidence are also characterized by high economic vulnerability and low literacy levels, which present additional challenges to ensuring IC (de Zoysa et al. 1998; Bayer 2000; Benatar 2002; Fitzgerald et al. 2002; Woodsong and Abdool Karim 2004; Molyneux et al. 2004). Special consideration must be given to ensuring that service providers continue to offer the most effective counseling possible to confirm that participants are fully informed, understand the information provided, and voluntarily consent to undergoing MC.

As outlined by Lavori and colleagues (1999), the IC process should encompass five key elements: 1) evaluation of a patient's competence to make a decision; 2) disclosure of relevant information about the proposed procedure; 3) assessing a patient's comprehension of the information; 4) ensuring the patient is choosing voluntarily; and 5) authorization of the patient's decision and, if choosing to undergo the procedure, signing of the IC form (Lavori et al. 1999).

\section{Ethical Issues Related to Minors}

Youth aged 15-24 account for more than 40 percent of new HIV infections worldwide each year (UNAIDS 2008). Therefore, the WHO/UNAIDS Montreux Consultation (WHO/ UNAIDS 2007) recommended prioritization of scale-up among adolescents and young men. The circumcision of minors, however, raises additional ethical issues. According to the Convention on the Rights of the Child, a child is defined as anyone under the age of 18 (UNHCHR 1989). Thus, many of the minors targeted for MC would qualify as children. Although a parent or guardian must provide written consent for minors to be circumcised, UNAIDS advocates that every effort should be made to ensure that minors are involved in the decisionmaking process, that they are fully informed of the risks and benefits appropriate to their age, and that they provide assent (UNAIDS 2008). 


\section{Study Objectives}

While the MC Partnership was operating in Swaziland, the Population Council (PC)

implemented an evaluation of the IC process between May and August 2010 to meet three study objectives:

1. Assess MC clients' comprehension of key concepts in the MC IC process;

2. Explore how males (adults and adolescents) who have recently undergone circumcision believe their experiences compared to their expectations based on MC counseling; and

3. Make recommendations for improving the effectiveness and efficiency of the IC process.

\section{METHODS}

A mix of quantitative (comprehension test pre-MC surgery) and qualitative methods (semistructured interviews [SSIs] one week post-MC) was used to address the study objectives (see Appendix A for objectives, associated research questions, and methods employed to address each). The study was implemented at selected MC sites in Swaziland, which were chosen in collaboration with the MC Partnership. The study was incorporated into the standard procedures for adult (18 and older) and adolescent (13-17 years old) clients undergoing $\mathrm{MC}$ at the participating clinics (see Table 1).

\section{Study Instrument Development}

Instruments were developed in collaboration with MC Partnership counselors and staff based on messages in counseling materials and information brochures given to clients. The comprehension test and SSI guide were pre-tested at Litsemba Letfu and FLAS in both English and SiSwati; minor changes were made to the SiSwati translations based on pre-testing. (Questionnaires are available at: http://www.popcouncil.org/projects/211_MaleCircumcisionPartnership.asp\#/ Resources.) The comprehension test was available in SiSwati and English, the most common languages spoken in Swaziland, and clients could choose between the two languages. SSIs were conducted in SiSwati, English, or a mixture of the two.

\section{Interviewer Training}

Quantitative (six) and qualitative (four) interviewers each attended a week-long training workshop conducted by Population Council staff from Swaziland, Zambia, and the US, with additional participation from MC Partnership counselors. Training included background about MC and the MC Partnership; exercises to elicit knowledge about HIV and AIDS; overview of study objectives; detailed review of study instruments and research consent forms in both languages, for all cohorts; training on hand-held computers (quantitative team); a tour and introductions at several participating sites; and role-plays to practice interviewing. Quantitative interviewers then conducted at least three test interviews among clients waiting to be circumcised, and qualitative interviewers conducted at least one SSI among clients waiting for their postoperative check-up at FLAS or Litsemba Letfu. 


\section{Recruitment}

For the comprehension assessment and the SSIs, clients were recruited on the day of their MC surgery, before undergoing any other procedures (see Table 1). After registering at reception, adults were told by clinic staff about the opportunity to participate in a study; interested clients were referred to Population Council interviewers who explained the study in detail. Interviewers obtained written IC for participation from clients participating in the quantitative comprehension assessment, who were interviewed on the same day. SSI participants were asked for written consent to be contacted several days after the MC surgery. Separate written consent was obtained for the actual interview, which was usually conducted at the seven-day post-MC visit, or in his home, if he preferred. Adolescents were eligible if they presented at the clinic with a parent or legal guardian. Written parental/guardian consent and adolescent assent were both required for study participation. (See Appendix B for recruitment targets and actual enrollment.)

Table 1. Standard procedures for clients undergoing MC at participating clinics

1. Clients register with reception.

2. Clients undergo MC counseling (generally group counseling, followed by one-on-one counseling).

3. All clients are encouraged to have CT during one-on-one counseling.

4. Clients undergo a physical exam conducted by a nurse to ensure they are eligible for circumcision and do not have any contraindications for MC.

5. Clients usually sign the IC form in the assessment room prior to entering the operating theater with the provider who performed the assessment.

6. Clients undergo the MC surgical procedure.

7. Clients are taken to the recovery area, where vitals are taken and pain medication is distributed.

8. Clients return for a 2-day post-MC follow-up visit, when the bandage is removed.

9. Clients return for a 7-day post-MC follow-up visit to ensure that the wound is healing well.

\section{Quantitative Methods}

\section{Research questions}

The primary research question for the comprehension assessment was: can at least 90 percent of $\mathrm{MC}$ clients correctly respond to at least eight out of ten questions (score 80 percent or better) on a ten-question true/false test? Secondary research questions explored whether there were significant differences in scores between the following sub-groups: adults vs. adolescents; clients attending fixed vs. outreach sites; clients attending rural vs. urban MC sites; and clients attending MC Partnership vs. FLAS sites. MC Partnership sites were defined as those that conduct MC solely through the MC Partnership or received significant ongoing financial, technical, and human resource support from the MC Partnership. Although FLAS receives support from the MC Partnership, it was not one of the four primary partners (PSI, MSI, Jhpiego, PC) and their efforts to provide MC services have been primarily independent from the MC Partnership.

\section{Sample size and study population}

In a post-test design, clients who had completed counseling, but had not yet signed the surgical consent form or undergone the circumcision procedure, were asked to respond to an interviewer- 
administered ten-question true/false comprehension test (see Table 2). Data on demographics, recruitment for MC, and type of counseling received (group, one-on-one, CT) were collected, and literacy and numeracy tests were administered.

Table 2. Comprehension assessment test: True/false comprehension questions

\section{Question}

1. A man who is circumcised no longer needs to use condoms during sex to prevent him from becoming infected with HIV.

2. Before a man's foreskin is removed during the circumcision procedure, one or more injections is given at the base of the penis to prevent pain.

3. A man can start having sex after being circumcised when he feels better, even if it is sooner than 6 weeks after his circumcision surgery.

4. Risks of the male circumcision procedure include pain, swelling, or bleeding during or after surgery.

5. Reviews or follow-up visits at the clinic after male circumcision surgery are to make sure the wound is healing properly.

6. All circumcised men are HIV negative.

[True]

[False]

[True]

. An HIV-negative man who is circumcised should continue to reduce his number of sexual partners to lower his chance of getting HIV.

8. Male circumcision can help lower a man's chances of getting penile cancer.

9. A circumcised man who is HIV positive cannot pass HIV to his female partner.

10. Male circumcision increases a man's chance of getting some STIs.

For the primary research question, a sample size of 86 people was needed to evaluate the null hypothesis: 90 percent of adult and adolescent MC clients are able to correctly answer at least eight of the ten true/false questions on the comprehension assessment, with the alternative hypothesis being that 80 percent of clients or less are able to do so. For the secondary research questions, a sample of 219 clients per arm was needed for 80 percent power to detect a 10 percent difference in scores between 1 ) adults vs. adolescents; 2 ) clients attending fixed vs. outreach sites; 3) clients attending MC Partnership vs. FLAS sites; and 4) clients attending urban vs. rural clinics. ${ }^{2}$ The sample size was rounded up to 225 per arm to account for missing data. Data from participants could be used for more than one comparison, which streamlined data collection and reduced the total sample size from 1,800 to 1,125. For example, adults who attended Litsemba Letfu could be stratified into fixed site, MC Partnership, and urban clinic for three different analyses.

\section{Data management and analysis}

Questionnaire responses were entered directly into hand-held computers programmed using Perseus Survey Solutions 7 for electronic data capture (EDC). Data were downloaded daily to the study coordinator's laptop computer, backed up onto an external hard drive, and emailed to the data manager. All devices and drives were password protected with alphanumeric passwords. Files

${ }^{2} \mathrm{~A}$ comparison of adult males attending CT and MC counseling prior to their day of surgery (219) vs. those attending CT and MC counseling on the day of surgery (219) was included in the original sample size calculation; however, this program did not go forward during the time of data collection. 
sent via email were protected using WinZip's 128-bit AES encryption. Only the secure data were distributed, making all reasonable efforts not to breach confidentiality.

Data were analyzed using Stata SE, version 10.1SE. A composite score was created for each participant based on the number of comprehension questions answered correctly. One point was given for each correct response, with scores ranging from zero (0 percent) to ten (100 percent). A variable was then created to code participants who answered eight or more questions correctly (80 percent) with a "1" (pass) and those who did not with a "0" (fail). Each subgroup analysis (i.e. adults vs. adolescents, etc.) included a comparison of mean scores overall, mean scores by question, and the percent of clients passing the test.

A one-sided t-test was used to test the null hypothesis that 90 percent of respondents could score 80 percent or better. A two-sided t-test was used to test individual questions separately and as a combined pass/fail indicator. Bivariate statistics and logistic regression were used to examine the relationship(s) between socio-demographic and other relevant factors that may have had an impact on scores.

\section{Qualitative Methods}

\section{Research questions}

The overarching research question was whether MC clients at participating clinics in Swaziland choose to undergo $\mathrm{MC}$ voluntarily and based on sufficient, accurate information. (See Appendix A for detailed research questions.)

\section{Sample size and study population}

SSIs were conducted among a convenience sample of MC clients, with the aim of interviewing a sufficient number of respondents until saturation was reached. The target was 30-40 interviews, 15-20 each with adults (18 and older) and adolescents (13-17 years old). Interviews were conducted one week post-MC surgery at the seven-day post-operative visit or at the client's home, according to his preference (see Appendix B for targets and actual enrollment).

\section{Data management and analysis}

Interviews were recorded and transcribed, and those conducted in SiSwati were translated into English. Transcripts were imported into ATLAS.ti (Version 5.7), a computer program that aids in the sorting and management of qualitative data. A codebook was developed based on key domains outlined during design of the research, with additional codes added as themes emerged from the interviews. To ensure quality and inter-coder reliability, each transcript was coded by at least two of the three team members. Coded transcripts were analyzed for key themes that emerged, primarily from responses to specific questions, as well as spontaneous comments from clients.

\section{Ethical Considerations}

The study protocol and amendments, IC forms, and data collection instruments were reviewed and approved by the Institutional Review Board (IRB) of the Population Council and the 
Scientific and Ethics Committee (SEC) of Swaziland. All participants provided written IC to take part in the study. MC clients were reassured that if they did not wish to participate, their health services or future medical care would not be affected. All interviews were conducted in private. Participant names were not entered into any data files, personal identifiers were removed from all transcripts, and all identifying information was kept in a secure location, to which only the field coordinator had access. After SSIs were transcribed, recordings were erased.

For adolescent participants, parental/guardian consent was sought first, followed by adolescent assent. Only adolescents whose parent/legal guardian was present on the day of the MC procedure were eligible to participate. Research involving adolescents was conducted based on guidance outlined in Ethical Approaches to Gathering Information from Children and Adolescents in International Settings: Guidelines and Resources (Schenk and Williamson 2005).

\section{Limitations}

First, the participants in this study (both quantitative and qualitative) were well educated and not necessarily representative of the population of Swaziland. Therefore, it may not be possible to generalize the results beyond this study.

Second, several challenges to data collection among adolescents may have had an impact on results. Before data collection commenced in May 2010, a campaign promoted by several MC Partnership sites had just ended; adolescents were returning to school and few were accessing MC services in the same volume as they had been during the campaign. Therefore, between the middle of May and the end of July 2010, only ten adolescents were interviewed, effectively suspending data collection among adolescents until the next school break in August. Once the youth circumcision campaign began again in mid-August, recruitment picked up significantly, and the bulk of adolescents were recruited in a three-week period. In addition, adolescents were only eligible if they came to the clinic with a parent or guardian. Many adolescents, however, had come for MC without their parents or guardians, who had already signed the surgical consent form prior to the day of surgery. Including only adolescents who were accompanied by a parent/ guardian on the day of MC limited the adolescents who were eligible and may have biased results in some immeasurable way.

Third, differential client flow at each clinic may have had an impact on study results. For example, it was not possible to achieve the target sample size at outreach clinics, because client flow was unpredictable. Often, fewer clients came to the sites than were scheduled, leading to a slower than predicted recruitment. On the other hand, at times when there was a high volume of clients, clinic staff and providers pressured interviewers to rush or stop interviews before completion; 42 adult interviews were stopped by clinic staff before completion (and not included in the analysis), which could have biased the results.

Last, qualitative data from the SSIs are from a small, non-random sample of MC clients. Clients were recruited from several participating clinics and represented a convenience sample of the first people agreeing to participate. It is possible that those who chose to be interviewed were biased in favor of MC and wanted to share their positive experiences, yet it is equally plausible that those interviewed were more likely to be dissatisfied and agreed to be interviewed to air their grievances. Therefore, findings should be interpreted as illustrative of the types of experiences men and adolescents report, rather than representative of the broader client population. 


\section{RESULTS}

Background and demographics are presented separately for the quantitative and qualitative components. Data on decisionmaking, counseling, and comprehension are presented from the quantitative comprehension assessment and the SSIs, whereas data on IC, procedure and recovery, and healing and wound care were only collected during SSIs.

\section{BACKGROUND DEMOGRAPHICS}

\section{Quantitative Comprehension Assessment}

Between May and August 2010, 953 MC clients (756 adults, 197 adolescents) completed the comprehension assessment. As illustrated in Figure 1, 99 percent of clients approached consented to participate in the study; 42 adult clients were unable to complete the survey because they were called in for the operation before they had the opportunity to do so.

Figure 1. Clients approached and completing quantitative comprehension assessment, by age and overall

1,001 approached

802 adults

199 adolescents

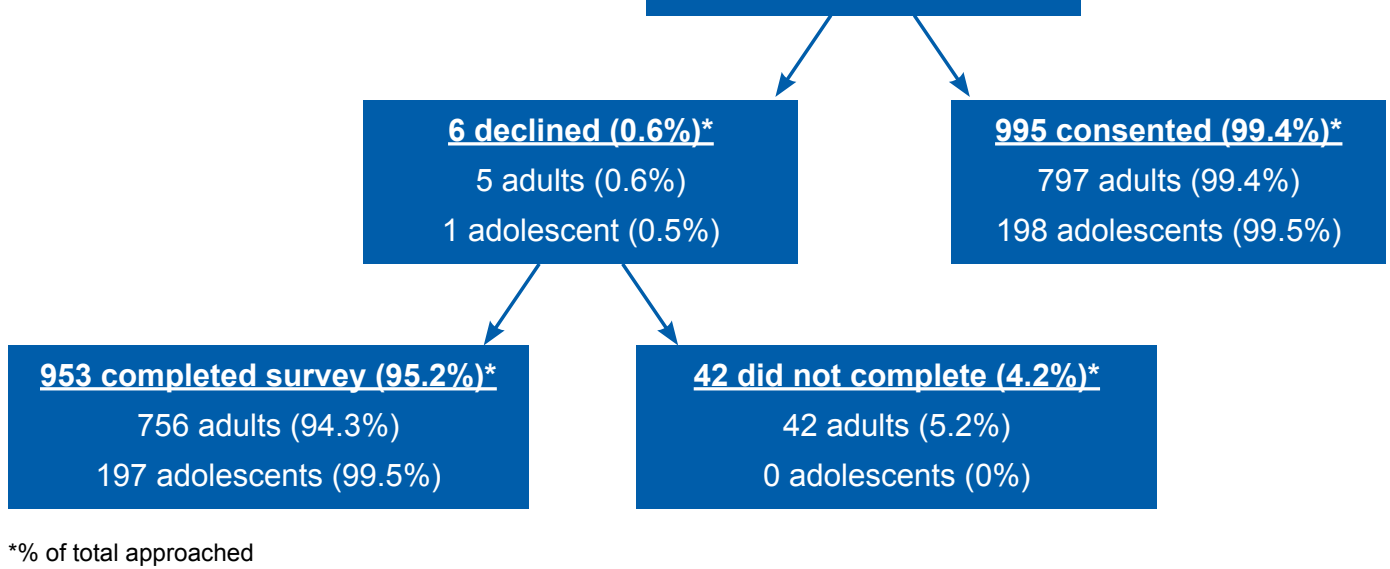

Clients averaged 23.4 years of age (25.7 years, adults; 14.8 years, adolescents), and the majority had never been married (77.5 percent, adults; 100 percent, adolescents). One-third of clients had completed at least secondary education (61.5 percent, adults; 4.1 percent, adolescents), and 91.5 percent of all clients passed both numeracy (98.4 percent) and literacy (91.6 percent) tests (see Appendix $\mathrm{C}$ for more detail). 


\section{Semi-structured Interviews with Male Circumcision Clients}

SSIs were conducted seven days post-MC with 30 clients (16 adults, 14 adolescents). The majority of the respondents were single ( 81 percent, adults; 100 percent, adolescents) and averaged 19.6 years of age (23.6 years, adults; 15.1 years, adolescents). Approximately 44 percent of adults had completed at least upper secondary school, and 38 percent had also completed some post-secondary education. Most adolescents were currently enrolled in junior or upper secondary school. The majority (53 percent) of interviews was conducted in SiSwati only; English mixed with SiSwati was used in 40 percent of interviews, and English only was used in 6 percent of interviews.

\section{DECISIONMAKING PROCESS}

\section{Information Sources}

\section{Quantitative comprehension assessment}

Adults who participated in the comprehension assessment had most frequently heard about MC from the media (44 percent), an interpersonal communication (IPC) agent (30 percent), or friends ( 26 percent). The majority of adolescents heard about MC at school (61 percent), through the media ( 24 percent), or from parents ( 20 percent). The majority of adolescents came to the clinic with a family member; about one-third came with a parent (31.5 percent), one-third with an older sibling (31.0 percent), and 18.8 percent with another relative (data not shown). Most adolescents (93.9 percent) were interviewed during a "Back-to-School" campaign in August 2010, while few adolescents came for MC services when school was in session between May and July 2010. There was no significant difference in sources of information, however, between the first ten adolescents and the majority interviewed in August. (See Appendix D, Figure 1.)

\section{Semi-structured interviews}

Similar to the quantitative findings, adults $(\mathrm{n}=16)$ most often cited friends and the media as their source of information about MC, and adolescents $(n=14)$ more frequently mentioned clinic outreach efforts at school, parents, or other family members. Several participants were aware of circumcision from interactions with friends, colleagues, relatives, or peers from ethnic groups in Mozambique and South Africa that practice traditional MC. A 15-year-old from Litsemba Letfu who learned about MC from someone who had been circumcised traditionally said, "I heard that most of the boys were dying in the mountains, thus I decided to come to the clinic to have the surgery done correctly."

A few clients described how their religious beliefs, or contact with a particular religious leader, had encouraged them to proceed with MC. For example, a 27-year-old from Litsemba Letfu explained that he had been encouraged "because the pastor told me that he has recently been circumcised," and a 26-year-old (also from Litsemba Letfu) said, "Biblically, God said to Joshua when they were about to cross river Jordan to the Promise[d] Land 'Remove the foreskins.' This means that circumcision is not new."

For other clients, however, religious beliefs seemed to have been a deterrent, prolonging the decisionmaking process. Two clients (one adult, one adolescent) said they had been afraid that if 
they chose to be circumcised, they would not be allowed into heaven. Both described how they had made sure this would not be the case before deciding to be circumcised. A 13-year-old from Litsemba Letfu explained how his pastor had said "those who have cut their manhood will not enter the kingdom of God" and then explained that he "ask[ed] my grandmother about this verse, and she said it is about those who have been castrated. I was relieved for I know that what I did is not castration."

Many adults said they had waited more than a year after hearing about MC before coming for the procedure, primarily because they felt they needed additional information to make a decision. Some adults also said they needed to find an appropriate time to schedule the procedure, such as after exams (university or matriculation), or when they could take time off from work. By contrast, the majority of adolescents came for $\mathrm{MC}$ within one month of hearing about services.

\section{Motivating Factors}

Most of the adult clients participating in SSIs listed more than one reason for choosing to be circumcised. The majority talked in general terms about disease prevention, with a minority specifically mentioning HIV prevention. A few men used vague language about wanting "to be safe" or getting circumcised for "the benefits." Several others said they did not believe themselves to be at risk for HIV - whether because of a negative HIV test result, currently being sexually abstinent, or using condoms 100 percent of the time. A more thorough review of transcripts, however, made it clear that minimizing exposure to HIV risk factored prominently in many clients' decisions.

A few adults reported seeking $\mathrm{MC}$ to address pre-existing medical conditions, including painful urination, difficulties with the foreskin, or other uro-genital problems. Several men also mentioned hygiene. Two men said they chose to get circumcised to reduce their partners' risk of cervical cancer; one man said it would be easier to use condoms without a foreskin; one man said he chose MC to prolong the time to ejaculation; and one said he was very worried about getting HIV because he has a sister who is infected. Most of the adolescents interviewed said they chose to be circumcised for STI and/or HIV prevention. Several adolescents also mentioned hygiene; one mentioned prevention of premature ejaculation; and one said he wanted to be circumcised because of a problem with his foreskin.

\section{Decision Comfort}

\section{Quantitative comprehension assessment}

Before responding to the true/false test, clients were asked several questions about the decision to undergo MC. The majority of adults (71 percent) reported being very comfortable with the decision, compared to only 48 percent of adolescents. Similarly, 73 percent of adults compared to only 26 percent of adolescents said they felt they had the opportunity to change their minds once they had made the decision (see Appendix D, Figure 2).

\section{Semi-structured interviews}

All of the adults and all except one of the adolescents said it had been their own choice to undergo MC, free from pressure or coercion. The adolescent who said it had not been his choice, 
a 16-year-old from Litsemba Letfu explained that his mother had made the decision for him. He explained that he ultimately agreed with the decision when his family told him that "being circumcised together with using a condom would mean even more protection for me as compared to when I only use a condom."

Most clients did not report feeling pressured to undergo MC by the fear that clinic services would otherwise be withdrawn. Several adults from FLAS, which provides a number of health services in addition to $\mathrm{MC}$, asserted that they trusted in the integrity and good intentions of the service providers. For example, a 32-year-old said that he had not been pressured and did not think he would lose services if he had not chosen to be circumcised "because this thing is voluntary, and they told us, so I do not think anything like that would happen." A 21-year-old (also from FLAS) said he believed that the clinic staff "would continue helping me, even if I did not get circumcised." Only a few clients expressed concerns about the potential loss of services if they had not been circumcised. Several adolescents seemed suspicious of clinic staff intentions. A 13-year-old from Litsemba Letfu said, "I have that feeling...they will be angry with me that I am not able to keep my words as nobody likes to be fooled." A 17-year-old from FLAS expressed anxiety about future employment opportunities if he changed his mind, saying "when you get circumcised, you are tested for HIV and that helps you know your status. Now MC is going to be introduced in work places such that when you are not circumcised, you will not get work."

Nearly all clients (15 adults, 13 adolescents) said they had received enough information to make a good decision about MC. A 21-year-old from Litsemba Letfu said, "I got clear information... they [counselors] did a recommendable job because you cannot do something which you don't know about. When you know about that thing, you become bold to do it." The majority of the adult clients ${ }^{3}$ said that it had been easy to choose MC because of the benefits, having sufficient information, being encouraged by friends or family, and having made a decision "from the heart." Among the few men who said the decision had been difficult, the most common reasons were fear of pain or complications; one client had been worried about the HIV test, and another had been afraid of the injection.

Regardless of whether clients felt it had been an easy or difficult decision, most adults and adolescents said they were comfortable with their decision, once they had made it. Several clients described being comfortable because they had made their decisions based on discussions with people they trusted and had all of the necessary information about the procedure and recovery. Many clients acknowledged that, even though they were comfortable with the decision itself, they had been nervous about potential complications and pain during the procedure, and how they would handle the healing process. Only two clients said they had not been comfortable with their decisions; however, they had been committed to going through with MC.

I was not comfortable [with the decision]. Like I mentioned earlier that the mere thought of having my manhood being cut was very, very scary. It took a bit of bravery as there was nothing I could do coz I had already made the decision...I would keep thinking if the doctor was not going to make a mistake and accidentally cut off my penis which would consequently make it dysfunctional... I heard that a real man is circumcised and I also wanted to be a real man, too.

Adult, aged 32, FLAS

${ }^{3}$ Adolescents were not asked consistently whether the decision was easy or difficult because it had been assumed that in many cases it was not their own decision. 
All but one of the adolescents said they had never considered changing their minds once they had made the decision to undergo MC. About half of the adults, however, said they had had second thoughts. A 21-year-old from Litsemba Letfu said he thought about changing his mind when he saw "the bed and the tools they were going to use. I thought very deep and finally decided to be bold and continue with the operation." A 23-year-old (also from Litsemba Letfu) was worried about HIV testing, "because it is not easy to be tested for HIV, more especially if you have been once engaged in unprotected sex." All clients—even those who had some doubts or had considered changing their minds-seemed to have gone through with the MC procedure because they had made a commitment to themselves. Many noted that if they had changed their minds, they would have regretted the decision because they would have remained at higher risk for HIV.

\section{COUNSELING}

\section{Type of Counseling Received}

The counseling package recommended by the MC Partnership includes group and one-onone $\mathrm{MC}$ counseling, and $\mathrm{CT}$. In practice, group counseling is offered at the discretion of the counseling team if there are a sufficient number of clients at the clinic. In addition, in accordance with the national MC policy of Swaziland, CT is routinely recommended and offered on a voluntary basis, but clients who opt out are not denied MC services (MOHS 2009).

\section{Quantitative comprehension assessment}

Most clients (89 percent) received one-on-one MC counseling (with or without group counseling) and CT, and the majority of clients (64 percent) received all three types of counseling recommended (see Figure 2). Almost all clients (96.6 percent) reported having CT, with 96.9 percent of adolescents and 87.5 percent of adults reporting that they had an HIV test. Few clients reported receiving exclusively CT $(n=11)$, one-on-one $(n=9)$, or group counseling $(\mathrm{n}=10)$. Most clients (97.6 percent, adolescents; 84.2 percent, adults) reported receiving oneon-one counseling in their most comfortable language; 86.9 percent of clients also received group counseling in their most comfortable language. 
Figure 2. Counseling package received by quantitative comprehension assessment participants, by age group and overall, $\mathrm{n}=953$

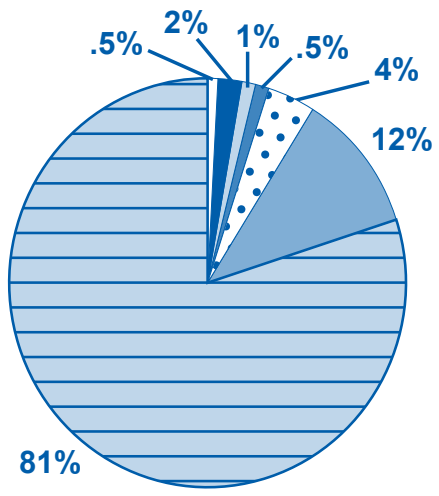

Adolescents $(n=197)$

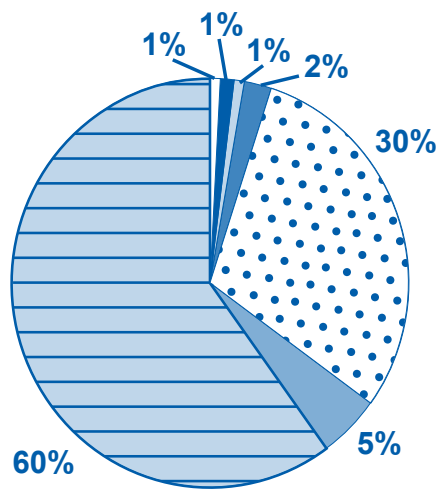

Adults $(n=756)$

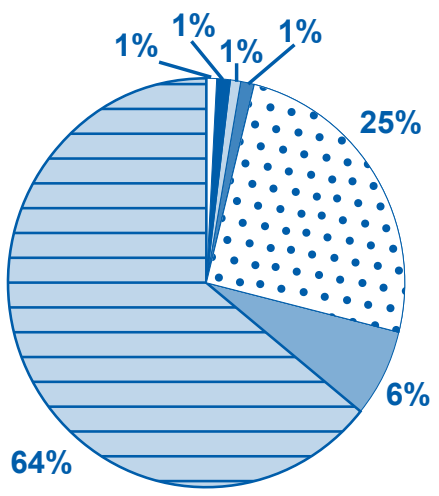

Total $(n=953)$

$\begin{array}{llll}\square \text { 1-on-1 only } & \square \text { Group only } & \square \text { VCT plus 1-on-1 } \\ \square \text { VCT only } & \square \text { Group plus 1-on-1 } & \square \text { Group plus VCT }\end{array}$

Note: May not add up to exactly $100 \%$ due to rounding.

As shown in Table 3, more than half of the 32 clients (28 adults, 4 adolescents) who did not have CT said they had declined. In contrast, the majority of clients who did not have one-on-one (77.1 percent) or group (69.3 percent) MC counseling reported that they had not been offered or given the opportunity to have that type of counseling. More than one-quarter of the clients who did not receive group counseling — primarily adults_-reported having been the only client present at the time of their MC procedure; one client reported having missed group counseling, because he had come late (data not shown).

Table 3. Reasons reported by quantitative comprehension assessment participants for not receiving one-on-one MC counseling, group MC counseling, and/or $\mathrm{CT}$, by age and overall

\begin{tabular}{|c|c|c|c|c|c|c|}
\hline & \multicolumn{2}{|c|}{$\begin{array}{c}\text { One-on-one MC } \\
\text { counseling }(n=83)\end{array}$} & \multicolumn{2}{|c|}{$\begin{array}{l}\text { Group MC counseling } \\
\qquad(n=257)\end{array}$} & \multicolumn{2}{|c|}{$\begin{array}{c}C T \\
(n=32)\end{array}$} \\
\hline & $\begin{array}{l}\text { Adults } \\
(n=54)\end{array}$ & $\begin{array}{c}\text { Adolescents } \\
(n=29)\end{array}$ & $\begin{array}{l}\text { Adults } \\
(n=245)\end{array}$ & $\begin{array}{l}\text { Adolescents } \\
\quad(n=12)\end{array}$ & $\begin{array}{l}\text { Adults } \\
(\mathrm{n}=28)\end{array}$ & $\begin{array}{l}\text { Adolescents } \\
(n=4)\end{array}$ \\
\hline$\%$ Not offered (n) & $75.9(41)$ & $79.3(23)$ & $70.2(172)$ & $50.0(6)$ & $28.6(8)$ & $75.0(3)$ \\
\hline \% Declined (n) & $7.4(4)$ & $6.9(2)$ & $1.2(3)$ & $8.3(1)$ & $60.7(17)$ & $25.0(1)$ \\
\hline$\%$ Other $(\mathrm{n})$ & $16.7(9)$ & $13.8(4)$ & $28.6(70)$ & $41.7(5)$ & $10.7(3)$ & $0(0)$ \\
\hline
\end{tabular}

\section{Semi-structured interviews}

Almost all clients (13 adults, 13 adolescents) reported receiving CT. More than two-thirds (13 adults, 8 adolescents) reported receiving one-on-one MC counseling (with or without group), and 13 clients (seven adults, six adolescents) said they had received all three types of counseling.

Clients seemed to have differing views about the purpose of HIV testing prior to MC. About half of the adults and two adolescents explained that it was important to know one's HIV status before being circumcised, because being infected with HIV could lead to lengthy wound healing 
or other risks. These clients seemed to understand that being HIV positive would not preclude someone from undergoing $\mathrm{MC}$, but that additional tests were necessary to ensure a person was healthy enough for the procedure.

Several adults, however, were unsure about whether HIV testing had been voluntary, and whether $\mathrm{MC}$ is advisable or permissible for an HIV-positive male. A 23-year-old from Litsemba Letfu was suspicious about the reason for the HIV test, saying,

I didn't understand why you had to get tested first.... They will circumcise you whether you have tested or not, then why do they want us to test first? You can get circumcised whether you are HIV positive or negative, so to me it looked like they just wanted to obtain their statistics.

A 24-year-old client, also from Litsemba Letfu, urged the clinic staff "to come up with a proper explanation about the testing for HIV before you have the procedure, because you can't say that an HIV-positive person doesn't heal."

Among adolescents, a 16-year-old from Litsemba Letfu said he had not known that he would have to get tested for HIV before having the procedure, and a 17-year-old from FLAS seemed to believe that HIV-positive men could not be circumcised at all, saying "I did not know you cannot do MC when you are HIV positive."

Among the clients who had opted out of CT, two adults said they had not been ready to be tested. A third adult, a 23-year-old from FLAS, said he wanted "more time more, especially with the HIV or VCT part."

\section{Impressions of Counseling from Semi-structured Interview Respondents}

Most clients reported primarily positive reflections about their counseling experiences, with many emphasizing that the most helpful aspect of counseling was the information they had received. Clients mentioned that $\mathrm{MC}$ counseling confirmed what they knew about $\mathrm{MC}$, or provided greater detail, helping to boost their confidence to undergo the procedure. A few clients also said they appreciated learning about how to take care of themselves, which apparently referred to personal hygiene and/or continuing to use condoms after MC. Some clients also mentioned learning new things during counseling; one client said he had not realized there would be an injection before the procedure to prevent pain, and another said he had learned that after MC, it would be easier to use a condom. A few clients mentioned that the most helpful part of counseling was learning that they would be protected (whether they understood "protected" to mean complete or partial) from getting HIV, STIs, and other diseases, or that their risk for diseases would be reduced.

Many clients said that finding out they were HIV negative (even if they had tested negative previously) was helpful because it allowed them to continue with the procedure. Several clients said finding out they were HIV negative was one of the most helpful aspects of counseling. Interestingly, eight adolescents mentioned renewed enthusiasm for undergoing $\mathrm{MC}$ upon finding out they were HIV negative, even though they all claimed that they were not yet sexually active. 
Although most clients reported that they were generally pleased with their counseling experiences, three clients ( 2 adults, 1 adolescent) were unhappy about not having had the opportunity to meet with a counselor alone, and two clients ( 1 adult, 1 adolescent) said the counselor had not adequately prepared them for the procedure or the subsequent healing process.

First of all, I didn't like the way we were counseled, because we were in a group and I don't think that is counseling. When you are counseling me, you need to get to me personally... then it was the issue of getting tested [for HIV] of which I wanted to ask about, but I couldn't because we were in a group.

Adult, aged 23, Litsemba Letfu

The nurse just talked to me about HIV testing and I told her that I was not going to take that test, so she then told me that I could go on and do the circumcision. She did not counsel me. Apart from the VCT thing, I did not go through or meet any counselor. It was just the information that I gathered up for myself.

Adult, aged 23, FLAS

The majority of adults said counseling had prepared them well for both the procedure and healing. Nearly all of the adolescents said they felt well-prepared for healing and wound care, yet only half said they felt they had been adequately prepared for the procedure. Most adults said the counselors had adequately answered all of their questions. Among adolescents, only four said their questions had been answered, three said there had not been enough time or they had not been given the chance to ask questions, because the doctors were waiting for them in the operating theatre, and seven said they had not had any questions. A 16-year-old from Litsemba Letfu suggested, "When they are counseling us, our parents should be there as well so that they could be able to assist us back at home."

\section{Presentation of Risks and Benefits}

The majority of clients (12 adults [one was not asked], 11 adolescents) said the counselors had presented risks and benefits adequately. A number of clients spontaneously mentioned that the balanced presentation of risks and benefits convinced them that the counselor was offering an accurate picture, which helped them feel even more comfortable about proceeding with MC.

I can say she was honest for she told us that there are risks and benefits of $M C$...the counselor gave us balanced statements... That made my mind to believe in what she was saying.

Adult, aged 26, Litsemba Letfu

I recall the lady giving me a paper in which I got to know the benefits of being circumcised and what was going to happen at the surgery. She also pointed out that it is not completely safe and I must say that it helped me to actually understand what the whole circumcision can do for me.

Adult, aged 32, FLAS

Although most clients said they had received good information about the risks and benefits of $\mathrm{MC}$, some clients, adolescents in particular, could not remember specific risks or benefits they had been told about (see "Comprehension" section below). Seven clients ( 3 adults, 4 adolescents) said risks had not been covered adequately, as counselors had focused more on the benefits. 


\section{Comfort and Rapport}

Nearly all clients (12 adults, 13 adolescents) said they had felt comfortable with the counselors, regardless of whether or not they thought the counselors had presented information adequately. Clients appreciated the counselors' demeanor, saying they were friendly and open, and not too serious. One client talked about how the counselor's use of humor had made people relax. Several clients also mentioned they had felt comfortable because the counselor reassured them of the confidential nature of their discussion. For example, a 21-year-old from Litsemba Letfu explained that "it is very hard telling a stranger your problems," but the counselor "assured me that she will not disclose the information to anyone."

For most clients, comfort extended to discussions of sexual activity. A 26-year-old from Litsemba Letfu explained that he was able to talk freely with the counselor saying, "If it happened that I looked at her face and found that she is too serious, you will find that I was going to lie to her. But because she was normal and smiling, I told her the truth." A 13-year-old, also from Litsemba Letfu said that he had been frightened during the discussion about sex, but that "she used a friendly tone which made me want to grasp everything." Only one adolescent, a 15-year-old from FLAS, said he had not been comfortable discussing sexual activity with the counselor "because she was old, ....it's just that talking about this with older people is not cool."

Among the clients who said that they had not been completely at ease with the counselors, two adults attributed their mixed feelings to the fact that their counselors were women. For example, a 24-year-old from Litsemba Letfu said it is hard to be open "when you are not familiar with a person, and more especially if she is a female...." Most clients, however, did not seem to have difficulty talking to a woman.

\section{Group versus One-on-One Counseling}

Many clients had positive things to say about the various types of counseling they had received, noting that each type had its own benefits. As articulated by a 14-year-old from Litsemba Letfu, "When in a group, you will be able to share your knowledge and one member can ask an important question which you never thought about, yet you need that information." A 23-yearold from Litsemba Letfu explained that "individual counseling is more about making informed decisions. It is where one has to decide whether to go for VCT or not. For me, it was important because I got to know my status."

Despite generally favorable comments about group counseling, a few clients noted some drawbacks, such as lack of privacy and struggling to ask one's own questions.

At times, when we ask [questions], she told us to keep them until we are on one-onone counseling session because you may find that you are the only one who has that particular problem and if she answered you, some of the clients will be scared to continue with the procedure.

Adult, aged 23, Litsemba Letfu

When you have something to say [in one-on-one counseling] you say it immediately, unlike the group counseling, you need to raise your hand. By the time they pointed at you to talk, you have forgotten what you wanted to say.

Adolescent, aged 13, Litsemba Letfu 


\section{COMPREHENSION}

\section{Results of Quantitative Comprehension Assessment}

Results of the quantitative comprehension assessment indicated excellent comprehension among clients preparing to undergo MC; 93.4 percent of MC clients scored at least 80 percent on the test (answered at least eight out of ten questions correctly), so the observed percentage of participants passing the test was significantly higher $(\mathrm{p}<0.001)$ than the null hypothesis, that 90 percent of clients could pass.

\section{Results by age group (adults versus adolescents)}

When stratified by age group, significantly fewer adolescents aged 13-17 than adults aged 18 or older (85.3 percent versus 95.5 percent) passed the comprehension test $(\mathrm{p}<0.001)$. Mean scores were also significantly higher among adults $(9.35)$ than adolescents $(8.82 ; \mathrm{p}<0.001)$. Figures 3 and 4 show the percentage of respondents who passed the test and the percentage who answered each question correctly (see also Appendix E, Table 1). Adults scored better than adolescents on eight out of ten questions, with statistically significant differences for seven of the eight. Only two questions were answered correctly by more adolescents than adults, but for those the difference was not statistically significant.

Figure 3. Comprehension assessment pass rates and mean scores, by age group and overall, $\mathrm{n}=953$

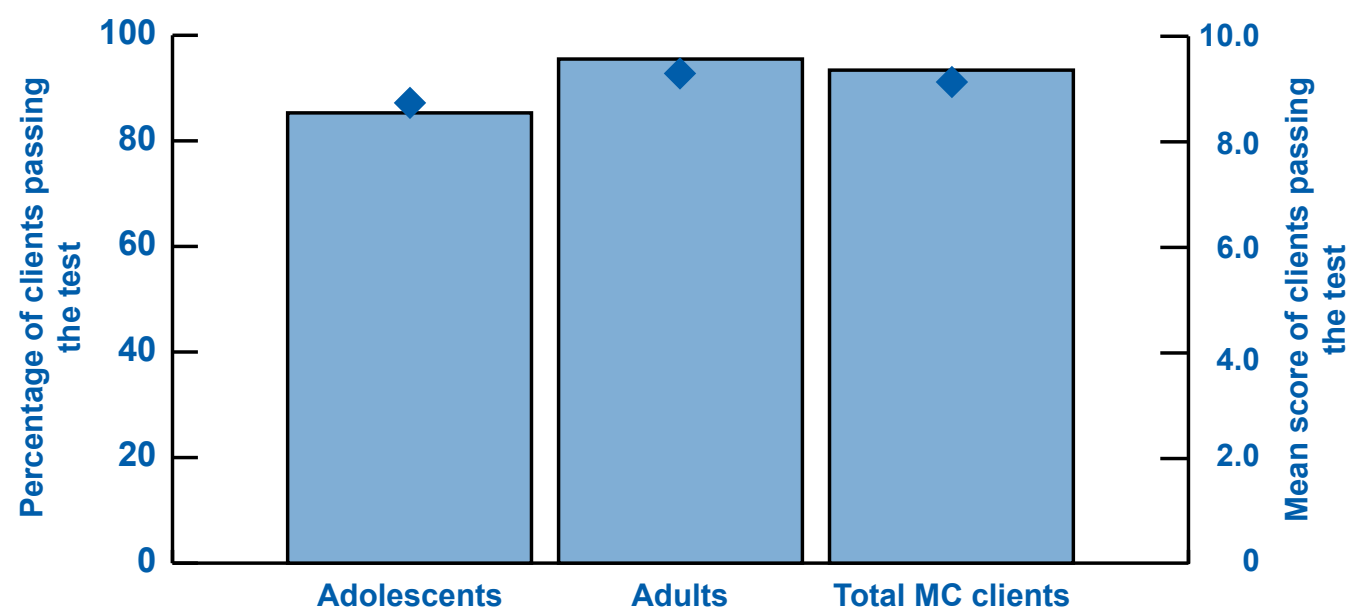

Note: Bar represents percentage passing test;

represents the mean test score

As illustrated in Figure 4, the question that the greatest number (98.7 percent) of adults answered correctly ("false") was that circumcised men no longer need to use condoms to prevent getting infected with HIV. The question answered correctly by the greatest number of adolescents $(94.4$ percent) was that the purpose of the follow-up visits is to ensure the wound is healing properly ("true").

The question that posed the greatest challenge for both adults and adolescents was about risks associated with MC surgery; only 86.9 percent of clients correctly responded that bleeding, pain, 
and swelling are risks of the MC surgery or healing period. A significant number of adolescents also responded incorrectly to two false statements: that all circumcised men are HIV negative, and that an HIV-positive man who is circumcised cannot pass HIV to his female partner. These questions were correctly answered by only 84.8 percent and 78.7 percent of adolescents, respectively.

Figure 4. Percentage of clients responding correctly to each question, by age group and overall, $\mathrm{n}=953$

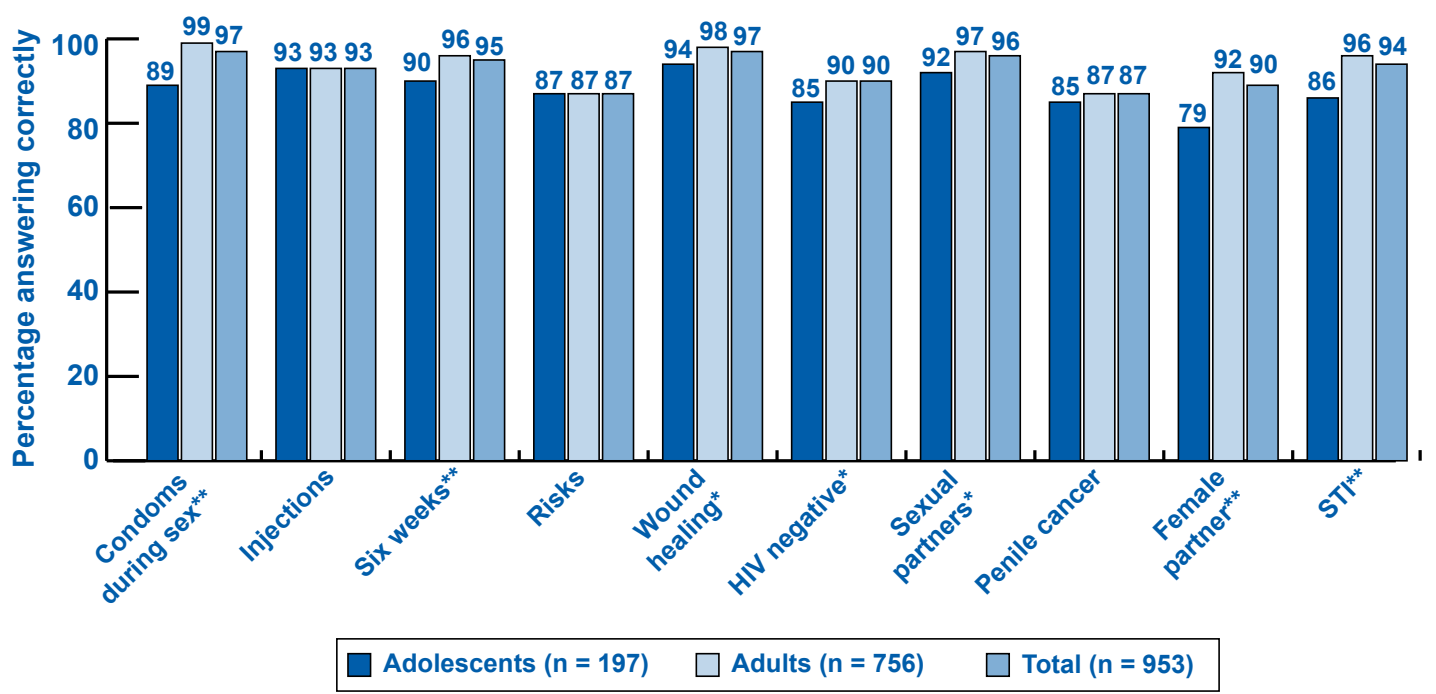

Notes: t-test comparing percentage of adults and adolescents responding correctly to each question; ${ }^{*} p<0.05 ;{ }^{* *} p<0.01$.

\section{Results by type of counseling received}

Although not part of the original analysis plan, pass rates were analyzed based on the type of counseling clients had received (see Appendix E, Figure 1). Clients who received all three types (group MC counseling, one-on-one MC counseling, and CT) performed the best, with 95 percent passing the comprehension test; those who received one-on-one counseling and CT, but no group counseling, did nearly as well, with 93 percent passing. Among clients receiving group MC counseling and CT, but no one-on-one MC counseling $(n=62)$, only 82 percent passed the test, a difference that was not statistically significant. However, among the adolescents in this last category $(\mathrm{n}=23)$, of whom only 61 percent passed the test, the difference was significant $(\mathrm{p}<$ 0.05 ), underscoring the importance of the one-on-one interaction between $\mathrm{MC}$ counselors and adolescent clients.

\section{Results by clinic}

The percentage of clients passing the comprehension assessment was also calculated by site, although this comparison had not been part of the original analysis plan. Mean scores and the percentage of $\mathrm{MC}$ clients passing the test was consistent across sites with the exception of Piggs Peak $(n=7)$, where only 57 percent passed (see Appendix E, Figure 2 ). 


\section{Results by clinic type, location, and affiliation}

There were no statistically significant differences in mean scores or percent of clients passing the test when comparing fixed $(\mathrm{n}=786)$ vs. outreach $(\mathrm{n}=167)$ type of clinic, nor urban $(\mathrm{n}=884)$ vs. rural $(n=69)$ location of clinic; however, it is possible that differences detected were not significant because of inability to reach the target sample in one of the arms (outreach, rural) for each of the two comparisons. In addition, there were no significant differences in the percentage of clients passing the comprehension assessment at FLAS sites $(n=288)$ versus MC Partnership sites $(n=665)$. The overall mean score at MC Partnership sites (9.31), however, was slightly higher than the mean score at FLAS sites (9.07), a statistically significant difference ( $\mathrm{p}<0.05)$. Details for all three comparisons are in Appendix E, Tables 2-4.

\section{Logistic regression}

Logistic regression was used to model predictors of passing the comprehension test. Adults were more than three times as likely as adolescents to pass the test, and clients who passed the literacy test were nearly three times as likely to pass as those who did not, both of which were statistically significant (see Table 4). Clients who heard about MC from a friend versus any other source were half as likely to pass the test. Marital status, education, counseling, and clinic characteristics were not associated with passing the test (the complete model is in Appendix E, Table 5).

Table 4. Summary of logistic regression illustrating variables found to be significantly associated with the odds of passing comprehension test, $\mathrm{n}=953$

\begin{tabular}{l|c|c|c|c|} 
Variable [reference group] & AOR & $95 \%$ Cl & $\mathbf{P}>|\mathbf{z}|$ & Std. Err. \\
Heard about MC from friend [No]/Yes & 0.44 & $0.24-0.80$ & 0.007 & 0.14 \\
Age [Adolescents (13-17)]/Adult (18+) & 3.45 & $1.35-8.77$ & 0.009 & 1.64 \\
Passed literacy test [No]/Yes & 2.92 & $1.30-6.60$ & 0.010 & 1.21 \\
\hline
\end{tabular}

Notes: $\mathrm{AOR}=$ adjusted odds ratio; $\mathrm{Cl}=$ confidence interval

\section{Concepts Explored in Semi-structured Interviews}

Comprehension was also explored among clients who participated in SSIs, conducted seven days after the MC procedure. Specific areas of inquiry included risks and benefits of MC, partial protection, the need to continue safer sex practices, instructions for wound care and healing, and impact of $\mathrm{MC}$ on female partners.

\section{Risks}

Client information brochures distributed by MC clinics explain that MC is safe when performed by a trained health professional (sample brochure can be found online at http://www.popcouncil. org/projects/211_MaleCircumcisionPartnership.asp\#/Resources). According to the brochure, most men do not experience any problems, and those who do report them to be "mild." Possible problems listed include reaction to the pain injection, minor bleeding, and some swelling and pain after the procedure. Additional information about risks is contained in the surgical consent forms, also available online. The FLAS consent form has a general statement about potential complications, but does not list specific risks; PSI's form lists the following risks: 
- Bleeding;

- Swelling;

- Pain;

- Infection;

- In very rare cases, permanent injury, numbness, loss of sensitivity, mutilation or total loss of the penis; and

- The risk of HIV or other infections if the client has sex before the wound is fully healedusually six weeks after the procedure.

All clients interviewed understood that there are risks associated with undergoing the MC procedure, whether or not these were discussed during counseling (see Table 5). Most clients (13 adults, 10 adolescents) said risks had been discussed during counseling. Three adults (two from Litsemba Letfu and one from MSI) and four adolescents (all from FLAS) said they had not been told about risks. Among clients who said that counselors had done a good job of presenting risks and benefits, however, four (one adult, three adolescents) could not remember the specific risks that had been discussed.

Several clients displayed knowledge of potential harm or discomfort resulting from the surgery without necessarily associating these potential adverse events with the word "risk." For example, a 27-year-old from Litsemba Letfu claimed he had forgotten the risks discussed during counseling. Later in his interview, however, he said that bleeding or swelling would lead him to seek help, indicating that he was actually aware of risks, but might not understand the term "risk" as used in this context.

Table 5. Risks and disadvantages of MC identified by adult and adolescent MC clients in SSIs, $\mathrm{n}=\mathbf{3 0}$

\begin{tabular}{l|c|c|c} 
Risk & $\begin{array}{c}\text { Adults } \\
(\mathbf{n}=\mathbf{1 6})\end{array}$ & $\begin{array}{c}\text { Adolescents } \\
\text { (n = 14) }\end{array}$ & $\begin{array}{c}\text { Total } \\
\text { (n = 30) }\end{array}$ \\
\hline Pain (of procedure, injection, healing) & 15 & 12 & 27 \\
Bleeding & 7 & 6 & 13 \\
Complications, including death & 7 & 4 & 11 \\
Swelling & 7 & 3 & 10 \\
Not caring for wound leads to infection & 1 & 5 & 6 \\
If diabetic, could prolong wound healing & 4 & 2 & 6 \\
Possible prolonged healing/differential timeframe for healing & 5 & 0 & 5 \\
Sex too soon could cause injury/prolong healing & 3 & 1 & 4 \\
If HIV positive, could prolong wound healing & 3 & 1 & 4 \\
Sex too soon could increase HIV risk & 2 & 0 & 2 \\
No sex for 6 weeks (disadvantage) & 1 & 0 & 1 \\
Confuses risk of MC with reduced risk of HIV & 1 & 0 & 1 \\
Infection & 0 & 1 & 1
\end{tabular}

Note: Participants could list more than one risk.

The most common risk mentioned was pain, which was often anticipated prior to counseling. During their interviews one week post-MC, clients tended to focus more on risks associated with the healing period rather than with the MC procedure, potentially because the relevance of these risks was greater at the time of the interview. 
Many clients - both adults and adolescents—said counselors explained that people heal differently and it might take longer for some people to heal than others. Some clients said they had been told that lengthy wound healing might be caused by undiagnosed diabetes (for which testing was not available), HIV, or other diseases. Risks related to diabetes and HIV did not seem to be a major concern to clients, however, which may have been because most clients undergoing MC knew their HIV status was negative, and probably assumed they did not have diabetes.

Adolescents seemed to be particularly concerned about the potential for the wound to bleed or "rot" (become infected) if they did not follow the instructions they had been given. Adolescents recruited from Litsemba Letfu talked about the importance of keeping the wound dry and the penis upright. A 15-year-old said, "I must keep the bandage dry, because if it [gets] wet, the wound will be rotten." A 13-year-old expressed his general fears about the consequences of not following instructions saying, "I asked myself, "what can I do if the wound will not heal or becomes rotten, such that I lose the whole penis?"

Although both adults and adolescents seemed more concerned about risks during healing and recovery, a number of clients (seven adults, four adolescents) also described being aware of potential surgical complications, including permanent injury to the penis. A 20 -year-old from FLAS said, "I was nervous, man...you see, there's no one [who is] perfect, and I was thinking, what if they make mistakes?" A 21-year-old from FLAS seemed to have conflated the risks of MC surgery with HIV risk reduction post-procedure, saying that the only risk that the counselor told him about was "the misconception that men usually have, that is thinking they can no longer use condoms." A 20-year-old from FLAS, explained his understanding of "risk" in terms of the clinic's lack of liability, saying that "if anything goes wrong, you do not have anyone to point a finger of blame at."

\section{Benefits}

Benefits of MC are outlined in the client information brochures (available at: http://www. popcouncil.org/projects/211_MaleCircumcisionPartnership.asp\#/Resources) and in counseling protocols, but are not listed in the surgical consent forms. The client brochure explains that MC reduces men's chances of getting HIV during sex with an infected partner, but that it does not provide 100 percent protection. Additional benefits listed in the brochure are:

- Reduces risk of STIs, including HIV, syphilis, genital warts, and herpes;

- Improved hygiene;

- Some protection against cancer of the penis; and

- Women whose partners are circumcised are less likely to get cancer of the cervix.

All of the participants were able to list at least one (correct) benefit of $\mathrm{MC}$, with most listing several benefits (see Table 6). All, except three clients from FLAS (one adult, two adolescents), said the benefits of MC had been talked about in counseling. The two adolescents from FLAS told the interviewer that benefits had not been discussed, while the adult client explained that because he had opted out of HIV counseling and testing, he did not receive details about the procedure itself.

HIV prevention was mentioned most frequently by both adults and adolescents, followed by STI prevention. Hygiene was mentioned by about half of the clients, although by more adults than adolescents. A 22-year-old from Litsemba Letfu said, "I like the fact that MC encourages hygiene, it makes keeping the penis clean easy. I also like it because they say it helps in reducing the chances of getting sexually transmitted infections." 
Table 6. Benefits of MC identified by adult and adolescent MC clients in SSIs, $n=30$

\begin{tabular}{|l|c|c|c|} 
Benefits & $\begin{array}{c}\text { Adults } \\
(\mathbf{n}=16)\end{array}$ & $\begin{array}{c}\text { Adolescents } \\
(\mathbf{n}=14)\end{array}$ & $\begin{array}{c}\text { Total } \\
(\mathbf{n}=\mathbf{3 0})\end{array}$ \\
\hline HIV prevention & 13 & 10 & 23 \\
STI prevention & 12 & 9 & 21 \\
Hygiene & 9 & 6 & 15 \\
Prolonged erection or other sexual improvement & 5 & 2 & 7 \\
Disease prevention, general & 2 & 4 & 6 \\
Protect partner from cervical cancer & 4 & 2 & 6 \\
Reduce risk of penile cancer & 1 & 0 & 1 \\
Delay sexual initiation & 0 & 1 & 1 \\
\hline
\end{tabular}

Note: Participants could list more than one benefit.

About one-third of the clients (primarily adults) also mentioned prolonged erection or improved sexual performance after MC. Most of this information had come from peers, however, and clients noted that counselors were either unaware of or told them that there was no scientific evidence that MC improved sexual performance.

... this may be something the counselor does not know, it's only males who know this - they say that when you are circumcised and have sex with a virgin it becomes easy to penetrate, you don't feel even the slightest pain... they say that you enjoy sex more when you are circumcised.

Adult, aged 25, MSI

This one guy said that when you are circumcised, you perform better in bed....he [counselor] said it wasn't scientifically proven.

Adult, aged 23, Litsemba Letfu

Often, one particular benefit, such as HIV prevention or correction of a medical condition, led clients to come for MC, and they learned about additional benefits during counseling.

When I came here, I wanted to reduce my chances of getting HIV, but the counselor told me about other benefits... she told me that $M C$ also reduces chances of getting STIs... I think the issue of STIs is more important because if you keep on getting STIs, that may lead into high risks of getting HIV.

Adult, aged 23, Litsemba Letfu

Seven clients (four adults, three adolescents) said they had learned during counseling that MC reduces women's risk of getting cervical cancer; however, only two clients mentioned reduced risk of penile or prostate cancer.

\section{Partial protection against HIV and other STIs}

The client information brochures state that MC "is not 100 percent protective. It only reduces the chances of getting infected with HIV." The surgical consent forms say "circumcision does not fully protect you from HIV and AIDS or other sexually transmitted infections." Counseling manuals include more information about the results of the three clinical trials mentioned at the outset, and cite the estimate that MC reduces risk of HIV infection by about 60 percent. 
All of the adult participants said MC is not 100 percent effective against HIV, and 14 correctly reported that MC reduces HIV risk by approximately 60 percent. A 22-year-old from Litsemba Letfu said, "it reduces the chances of getting HIV—not completely—but only reduces the chances by 60 percent." A 20-year-old from FLAS said MC reduces the chances of getting HIV by 60 percent, which meant that he "was only left with 40 percent to make sure that I'm safe."

Although the concept of partial protection against HIV was well-understood among this group of adults, a 23-year-old from Litsemba Letfu acknowledged that the concept could be confusing, saying that "this 60 percent and 40 percent thing is quite confusing to some people who don't understand math."

Most adolescents also seemed to understand that $\mathrm{MC}$ is only partially protective against HIV. Of those, half knew the correct level of protection, whereas others either guessed at the level of protection, ranging from 20 to 95 percent, or were not asked to specify the level of effectiveness. Three adolescents incorrectly believed MC to be 100 percent effective.

Of the 14 adults who mentioned STI prevention as a benefit of MC, all except one seemed to understand that $\mathrm{MC}$ is also only partially protective against other STIs. Only one client, a 26-year-old from Litsemba Letfu, seemed to think MC is fully protective against other STIs, saying "Other STIs, you don't get at all if you are circumcised." Although none of the counseling materials specifies the level of protection against STIs, three men thought MC provides 60 percent risk reduction against STIs, as well as HIV.

Nine of the 13 adolescents who mentioned STI prevention as a benefit understood MC to be only partially protective against other STIs; three believed MC was 100 percent protective against all STIs, including HIV; and a fourth, a 15-year-old from Litsemba Letfu, believed MC was 100 percent effective against STIs, but only partially protective against HIV, saying, "I will be protected from STIs and have less chances of getting HIV." Of the nine adolescents who understood that MC is partially protective against STIs, one attributed the same 60 percent level of protection to other STIs, as well as HIV.

\section{Mechanism of protection}

A theme that emerged in about half of the adolescent interviews (and a few adult interviews) was that removal of the foreskin enables males to be "clean" and eliminates places for diseases to "hide" in the body. Despite stating that MC is only partially protective against HIV, comments from a number clients seemed to indicate their belief in the absolute elimination of the mechanism of transmission of HIV and other STIs. For example, a 13-year-old from Litsemba Letfu said, "If you're not circumcised, the foreskin acts as a hiding place for infections and the virus can easily get into you, but if you are circumcised, there is no place for infections to hide." Similarly, a 23-year-old from Litsemba Letfu said the counselor had told him that "some diseases hide in the foreskin and they penetrate through your body. If you are circumcised, those viruses won't get the chance to get into you." A few clients seemed to have a clear understanding that removal of the foreskin reduces risk but does not eliminate it completely, although none talked about the continuing risk of sexual transmission from exposure to blood or vaginal secretions during sex. 


\section{Protection for female partners}

Client information brochures state that "women whose partners are circumcised are less likely to get cancer of the cervix." Neither the brochures nor the surgical consent forms mention that MC provides only indirect protection against HIV for women, or that female partners may be at increased risk of HIV if they have an HIV-positive partner who initiates sexual activity earlier than six weeks post-MC (Wawer et al. 2009).

When asked whether MC protects female sexual partners from HIV, about one-third of clients (six adults and six adolescents) said the topic had not been discussed in counseling, and the interviewers often did not follow up to see what the clients thought on their own. Among the ten adults who talked about HIV protection for female partners, four believed MC to be protective. A 21-year-old from Litsemba Letfu said, "If I am protected it means that she is automatically protected...." A 32-year-old from FLAS seemed to imply that he thought his partner would be partially protected from getting HIV from him, but that she was at risk from other transmission routes. He explained that female partners are protected to some extent because "the foreskin is no longer there to lock in unwanted substances like HIV, which can be transferred to the lady during sex if the man is not circumcised" but that female partners are not completely protected "as HIV is not only passed through sex."

The other six adults seemed to understand correctly that MC has not been shown to protect female partners against HIV. Two clients explained that if MC provides only partial protection for males, then their partners would also be only partially protected. A 25 -year-old from MSI said, "She can get it [HIV], so a condom is important to use."

Two adults correctly explained that MC protects female partners from HIV and other STIs, but only indirectly. A 21-year-old from FLAS said that MC cannot protect a woman from HIV if her partner is infected, saying MC protects women from HIV "as long as the male does not have it [HIV]." Similarly, a 26-year-old from Litsemba Letfu said, "the women will benefit in the sense that the partner has less chances of being infected. As a result, the woman will receive less infection." Only one adult, a 23-year-old from Litsemba Letfu, clearly articulated that cervical cancer is the only disease that MC has been shown to prevent in women, saying "if you are circumcised, you reduce the chances of causing cervical cancer in her when you have sex.... There is no other protection to your partner if you are circumcised."

Of the eight adolescents who talked about the effect of MC on female partners' risk of HIV, seven seemed to understand that protection for females is indirect. A 14-year-old from Litsemba Letfu explained that, "it depends on whether the man is infected or not. If he is positive, the woman is not protected [from HIV]." A 17-year-old from FLAS said, "It is the man who is circumcised and if he is not faithful to his partner, there is no way that the girlfriend won't get the virus." The one adolescent (a 13-year-old from Litsemba Letfu) who thought MC protects female partners-even when condoms are not used-said, "because the virus hides in the foreskin and if you engage in sex without a condom, you will pass the virus to the woman and if circumcised, the woman will not be infected."

\section{Safer sex strategies}

Information about the need to continue safer sex practices is contained in client brochures and surgical consent forms. The brochure explains that after $\mathrm{MC}$, it is still necessary to protect oneself from HIV by abstaining from sex, remaining faithful to one partner whose HIV status you know, reducing multiple concurrent partnerships, and correctly and consistently using a condom. All 
of the adults and all except one adolescent acknowledged the need to continue safer sex practices post-MC; most could identify at least two strategies.

\title{
Condoms
}

Nearly all clients acknowledged the importance of condoms post-MC. Five clients (three adults, two adolescents) explained that MC is only partially protective, so they would still be at risk if they did not use condoms. A 25-year-old from MSI said that although "the chances of getting infected with HIV are reduced by 60 percent, a condom should always be used...you must not take any chances because you are circumcised."

Several clients had alternative reasons or explanations for condom use post-MC. For example, a 21-year-old from FLAS said condoms were important "for family planning to avoid unwanted pregnancies [because] I am a Born Again Christian, I [have] to wait or abstain until I am married." A 32-year-old (also from FLAS) seemed to believe the need for condoms was temporary, explaining that after the six weeks of abstinence post-MC, one should be "using a condom the three months after that."

\begin{abstract}
Abstinence
When asked how they could protect themselves against HIV once they had been circumcised, about half of the clients (six adults, eight adolescents) mentioned abstinence. Among the adults, in general, there was recognition that abstinence is the only way to be 100 percent protected from getting HIV through sex, even if they were not abstinent themselves. The 21-year-old Born Again Christian from FLAS, who believed in abstinence until marriage, said "My risk is low coz I abstain.....and it is the greatest weapon."

Most adolescents, all of whom reported not yet having initiated sex, were currently relying on abstinence as their primary HIV prevention strategy and indicated that MC had not changed anything. A 17-year-old from FLAS said, "The counselor said it does not mean that you are safe when you are circumcised...the best thing to do is to abstain or else use a condom." Another 17-year-old from FLAS said, "You only have sex when you have a wife." Because they had not yet initiated sex, adolescents were asked whether they thought they would start sooner now that they had been circumcised. The majority of adolescent clients said that being circumcised would not alter their behavior. Many indicated that they were too young or too busy for sex, regardless of their circumcision status. For example, a 16-year-old from Litsemba Letfu said "I have to grow old first," and a 17-year-old from FLAS said "I had not thought about having sex anytime soon." A few adolescents noted that being circumcised was not going to lead them to initiate sex sooner, specifically because they would still have to use condoms anyway.
\end{abstract}

\section{Partner reduction/monogamy}

Most clients (14 adults, 13 adolescents) acknowledged the continued need for reducing the number of sex partners after circumcision. Many adults, when asked if doing so is important post-MC, linked partner reduction with fidelity. A 26-year-old from Litsemba Letfu said, "Now I am honest to my wife and she is honest to me as well." A 25-year-old from MSI said, "What is most important is to have one partner, not to have a lot. It is also important for my partner to have only me because there [are] a lot of diseases out there." A 32-year-old from FLAS, who implied that MC would protect him if he were to have more than one partner, said, "You see sometimes it happens that we as men have affairs outside marriage and [I] heard that getting circumcised can protect me to some extent." The interviewer did not follow up by asking the client whether it was important for him to reduce partners. 
The majority of adolescents also recognized the need for fidelity once they started having sex. Not previously having had sex or sexual partners, however, some adolescents were confused about the meaning of partner reduction. A 17-year-old from FLAS said, "They can have a lot of partners if they want, but they should use a condom, and when you have had enough, then take a wife."

\section{Voluntary CT}

Although none of the clients mentioned the need for ongoing HIV counseling and testing after $\mathrm{MC}$, with probing, nearly everyone acknowledged that periodic CT was advisable. Clients were asked to explain why ongoing testing was important, and comments from several clients seemed to indicate that they understood they were still at risk of getting HIV, but from transmission routes other than sex. A 21-year-old from Litsemba Letfu said CT "is important so that you know your HIV status and besides, you can get HIV by being in contact with infected blood, apart from sex" and a 20-year-old from FLAS said CT is important "because you do not get HIV only through sex, but also other ways...like sharing sharp objects." And, a 23-year-old from Litsemba Letfu said that it is important to get tested after MC because "you need to confirm, for you may find that you tested negative because of the window period." It was not clear, however, if he understood that continued CT was recommended—even after three months.

\section{Post-procedure abstinence}

Client information brochures explain the six-week waiting period post-MC before having sex or masturbating so the wound can heal completely. The brochure explains that initiating sex prior to six weeks could prolong healing or increase HIV risk. The same information is contained in the PSI surgical consent form and the post-surgical booklet given to clients.

Adult clients universally understood that they were required to abstain from sexual activity for six weeks post-MC to allow sufficient time for the wound to heal. Clients seemed to understand that the wound might look as if it had healed externally before it was completely healed internally.

Many adult clients (and one adolescent) described the potential consequences of engaging in sexual intercourse before the prescribed six-week period of abstinence. A 26-year-old from Litsemba Letfu explained that "the wound will not heal if you will decide to have sex before the six weeks was over." Only two adults, both from Litsemba Letfu, seemed to recognize that having sex too soon could also increase the risk of HIV infection. A 21-year-old said, "Before the six weeks, I must not engage to sexual intercourse because I might be at risk of getting HIV."

Although none of the adolescents interviewed reported that they were sexually active, the majority remembered the six-week timeframe to allow for full recovery and seemed to understand the reason for waiting. A 13-year-old from Litsemba Letfu said the counselor had told them that one "should not have sex before six weeks were over because if you do you will disturb the healing, then you start bleeding again." Three adolescents said they did not know or could not recall the exact timeframe for post-procedure abstinence, and several adolescents indicated that although the counselors had told them the waiting period was six weeks, they thought it would be wise to wait even longer. A 17-year-old from FLAS said the doctors had explained that clients could initiate sex "after six weeks, but according to me, it can be two to three months so that the wound heals well. This is because if you start having sex earlier than the said time, there can be some problems with the wound." 


\section{INFORMED CONSENT}

Informed consent data are from the semi-structured interviews conducted seven days post-MC surgery with 30 clients (16 adults, 14 adoelscents).

\section{Differences between Informed Consent Forms by Clinic Site}

Most clients were recruited from PSI's Litsemba Letfu Clinic or from FLAS clinics in Mbabane and Manzini; two adults were recruited from MSI's clinic in Manzini, and no clients participating in SSIs were recruited from any of the outreach sites. Clients' comments about IC-both the forms and the process-reflected differences between the content of the IC forms used by the different institutions. To help frame participants' comments, Table 7 presents a summary of differences between the IC forms used by PSI and FLAS. The consent forms are available online at http://www.popcouncil.org/projects/211_MaleCircumcisionPartnership.asp\#/Resources.

Table 7. Summary of surgical IC forms used by PSI and FLAS

\begin{tabular}{|l|c|c|} 
Elements contained in form & PSI & FLAS \\
Basic information about circumcision procedure & Yes & No \\
Basic information about circumcision aftercare & Yes & No \\
Instructions to attend follow-up visits & Yes & No \\
Instructions for adverse events & Yes & No \\
Instructions to avoid sexual activity for at least six weeks & Yes & Mentioned but \\
Risks and benefits of MC & Yes, listed & not listed \\
& & Yes \\
Reminder that MC does not provide full protection from HIV & Yes & Yes \\
Reminder of the importance of safer sex practices & Yes & Yes \\
Statement that in the case of (rare, but possible) medical & No & \\
complications following MC, client will not sue provider & & \\
\hline
\end{tabular}

\section{Perceptions of Consent Form and Process among Adult Clients}

Almost all adult clients acknowledged that they had signed an IC form before the MC surgery, although perceptions of the form's contents varied. As noted in the introduction, the IC process includes the following elements: 1) the provider gives relevant information about the procedure to the client; 2) the provider ensures that the client comprehends the information; 3) the client chooses to undergo the procedure, or not, based on his or her comprehension of the information provided; and 4) the client signs the IC form to authorize his decision to have the procedure. These discrete elements were rarely reflected in client perceptions of IC.

Five adults, who said that they had read the IC form and had thought about what they had signed, explained that their signatures represented their agreement to undergo the MC procedure, indicating an understanding that signing the IC form authorized providers to perform the circumcision. Comments for these clients, however, did not indicate whether they understood that their choice had been based on comprehension of risks and benefits and had been made voluntarily. A 21-year-old from Litsemba Letfu explained that the form "wanted me to fill in my name, cell phone number and my signature. This was to confirm that I have agreed to be circumcised." 
Only one adult gave an answer that showed he had truly appreciated all of the elements of IC (although he also referred prominently to release from liability):

\section{Participant: Yes I did [sign].... It was to emphasize the aspect of voluntariness and the fact that there will be no compensation if ever any complications arise. So you cannot sue the clinic on that occasion. ... to me it meant that I chose this myself and it was I was aware of the inherent risks. \\ Interviewer: Did you think the counselor did a good job in explaining the risks and benefits of the MC procedure? \\ Participant: It was ok because I remember that we were given some form that told us about MC not being a guarantee to protection from HIV and also made us aware that the doctor can make mistakes, also depending on the type of person the individual is which means different reactions.}

Adult, aged 32, FLAS

Ten adults asserted that undergoing the $\mathrm{MC}$ procedure had indeed been their own choice, made voluntarily without external pressure, but they did not necessarily associate their choice with the IC process. Half of the adults (six from Litsemba Letfu) expressed confusion about the form (or the question asking whether they had signed a form), denial about signing anything, or admitted that they had not read the form thoroughly before signing it because of time pressure.

Participant: Yes I did [sign] some form after doing the tests... we sign and there is actually no time to read, but from reading the topic I could see that it's about consent to getting circumcised... Nothing was explained to me, so I would say... it meant that I was agreeing to be circumcised. I would be very surprised if there was a clause talking about something else because the form wasn't explained to me. I'm a bit concerned about the contents of the form.

Interviewer: So you mean you never read it?

Participant: No I didn't read it because they just tell you to sign it. When they give it to you they are already standing and waiting to take you to the surgery. So really you don't have enough time to read the form.

Adult, aged 23, Litsemba Letfu

\section{Liability for adverse events}

The consent forms used by FLAS and PSI seem to indicate a difference in how adverse events are handled at clinics affiliated with the two organizations. PSI's IC form, which is used at the Litsemba Letfu clinic, lists potential adverse events and states that the client "will receive any treatment necessary for any problems that are found" at follow-up. The PSI IC form reiterates that the clinic remains responsible for providing any follow-up care required to $\mathrm{MC}$ clients in the case of any adverse events. The IC form used by FLAS clinics, on the other hand, states that complications (unspecified) from MC surgery are rare, but possible, and explicitly asks the client to agree that "if a complication occurs, I will not take legal action against the health facility or the surgeon." There is no mention about care and support if an adverse event occurs.

The differences in the two consent forms are reflected in clients' comments. Of the five adult MC clients circumcised at FLAS clinics, four stated that they understood the main purpose of the IC form to be a release of liability for the clinic, in the event that they should experience any adverse 
consequences following the MC surgery (the fifth claimed not to have signed an IC form). A 20-year-old said signing the form "meant that I am not going to blame or claim from anyone if there are going to be any problems. So I went through with the procedure aware of that kind of thing." Another 20-year-old explained, "To me it just meant that whatever happens, it is my own problem and I have to face that alone."

Comments from clients at the Litsemba Letfu clinic, by contrast, appeared to reflect a more supportive environment around the possibility of complications, since clients knew that they were assured of appropriate medical care. For example, a 27-year-old from Litsemba Letfu said that if he experienced problems during healing, "I was going to come back [to] the clinic to report my problem, because I was given an emergency number to contact."

\section{Perceptions of Consent Form and Process among Adolescents}

Perceptions of the IC process among adolescent clients varied. Only two adolescents indicated that "informed consent" meant an agreement (theirs or their parent's/guardian's) to be circumcised; no one mentioned comprehension or voluntariness. Probing by interviewers revealed that six adolescents had asserted that the decision to undergo MC had been voluntary. For example, a 13-year-old from Litsemba Letfu made it clear that he was the one who had decided to be circumcised, saying, "Yes, it was my own choice to go for MC surgery, because I am the one who ask[ed] for permission from my mother and she agreed."

Most adolescents recalled that their parent or guardian had signed a consent form before the MC procedure could take place. ${ }^{4}$ Adolescents reported that parents, older siblings, and, in one case, a grandmother had signed the form for them. If the parent/guardian had been unable to come to the clinic to sign the form on the day of the procedure, several adolescents reported that they had taken the form home for signature and returned on another occasion for the surgery, or that the recruiting team visiting the village had brought consent forms to the parent at home. ${ }^{5} \mathrm{~A} 17$-yearold from FLAS, who said that his father had signed the IC form for him, but had not been at the clinic when he was circumcised, explained, "I took the form and went home with it before circumcision." A 14-year-old client reported that a peer educator had signed the IC form as his guardian.

Although most adolescents were aware that a consent form had been signed on their behalf, they were not necessarily aware of the content of the forms:

Interviewer: What was it [the IC form that your father signed] all about?
Participant: I don't know because I did not read it. ... It means that I have come
for the MC surgery.
Interviewer: Did they explain the form to you?
Participant: They did not. They ask me if my dad had signed, and I told them that
I saw him talking to the lady at the reception.

\footnotetext{
${ }^{4}$ The majority of interviews were conducted during a Back to School campaign, when a modified consent form was used for adolescents. If an adolescent came to the clinic with a signed consent form, the counselor would call the parent/guardian to ensure that their questions were answered and to verify that they had signed the form.

${ }^{5}$ All adolescents in the study had to have been accompanied by a parent/guardian to be recruited on the day of the MC procedure; it is likely, therefore, that the person who consented for study participation was not the parent/guardian who had consented for the MC surgery.
} 
Interviewer: Did you sign anything before the surgery?

Participant: No, I did not sign anything.

Adolescent, aged 15, Litsemba Letfu clinic

Five adolescent clients (four of them from FLAS) asserted that they had also signed some type of consent form themselves, but it was not clear what form they were referring to, because there is no specific assent form designed for minors to sign. These adolescent clients may have signed a form designed for adult clients to consent to $\mathrm{MC}$, or they may have signed a consent form agreeing to undergo voluntary HIV counseling and testing. ${ }^{6}$

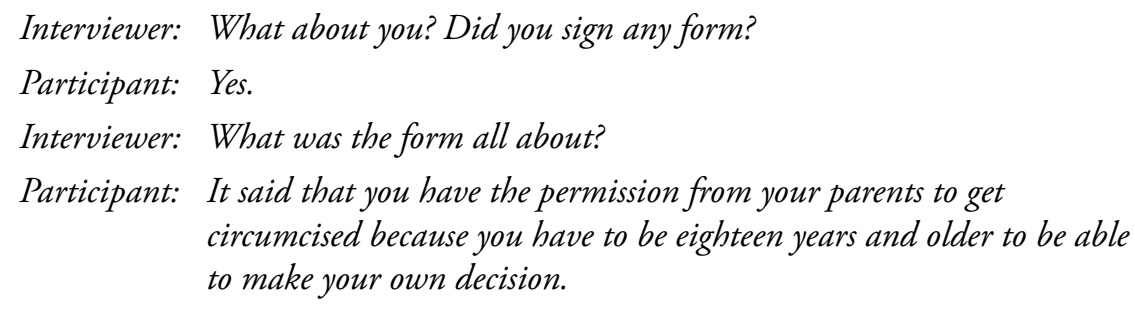

Adolescent, aged 17, FLAS

Interviewer: Did you sign anything?

Participant: Yes, I did and my signing meant that I agree with everything that was written on it. After signing, the counselor told us everything that we needed to know about circumcision.

Adolescent, aged 17, FLAS

Two adolescents said that they had signed a form without understanding what it was about, and others could not remember what they had signed.

\section{PROCEDURE AND RECOVERY}

\section{Preparation for Procedure}

Most of the 16 adults who were interviewed one week post-MC said they had been well-prepared for the MC procedure. A 26-year-old from Litsemba Letfu said, "You can see that the clinic staff is well equipped about MC operations. There is nothing that I feel they should have done differently." A 22-year-old, also from Litsemba Letfu, said, "I went through to the surgery with confidence because we were told everything that was going to happen. We were told every step." Only three adults had not felt prepared; one had opted out of CT and said he did not receive any other counseling about MC; the other two adults had been generally satisfied with counseling, but felt they had not been given adequate information about the procedure itself.

\footnotetext{
${ }^{6}$ Adolescents 16 and older are routinely offered CT; those under 16 are required to have parental/guardian consent. Almost all of the adolescents participating in the SSIs had received CT, even those under 16. If their parents/guardians had signed the surgical consent forms earlier, and did not accompany them to the clinic, it is possible that they may have consented to CT on their own.
} 
About half of the adolescents said they had been adequately prepared for the procedure, as articulated by a 17-year-old from FLAS who said, "I was comfortable throughout the day [of the procedure] because I knew what was going to happen...I was not afraid." As noted above in the section on counseling, half of the adolescents said that they had not had any questions, yet also indicated that, upon reflection, they had not been given complete information about the procedure itself. Several adolescents had been especially confused about how the anesthesia was administered. A 13-year-old from Litsemba Letfu had been afraid because "I thought they will cut the foreskin without any anesthesia." A 16-year-old from Litsemba Letfu had thought "that they would start with the cutting, then inject you afterwards for the pain, but they injected me first before the surgery." A 15-year-old from FLAS said, "It was not as I expected it to be. I thought I was going to be put to sleep and then they do it."

\section{Anesthesia}

A majority of clients (nine adults, seven adolescents) identified the anesthesia injection(s) as being the most difficult part of the procedure. A 22-year-old from Litsemba Letfu said, "The injection part [was] very difficult because there was so much pain involved." Several clients commented that they had been led to expect only a single injection, but were shocked and upset to receive multiple injections. A 13-year-old from Litsemba Letfu said, "It wasn't similar to what I expected, because I thought they inject you once, but they did it many times." A number of clients who had received multiple injections, however, commented that they had not felt anything after the first injection.

\section{Surgery}

The majority of clients (ten adults, eight adolescents) identified the removal of the foreskin to be the easiest part of the procedure, because the anesthetic had taken effect by that point. A 22-yearold from Litsemba Letfu said, "I think the easiest part was the cutting because there was no pain at all."

Most clients said the cutting of the foreskin was less painful than they had expected. A 23-yearold from Litsemba Letfu said, "I thought it was going to be more painful. I didn't believe when they say it will not be painful." Two clients from Litsemba Letfu (one adult, one adolescent), on the other hand, said that they had experienced pain during suturing as the anesthetic began to wear off. A 22-year-old said the most difficult part of the procedure "was the stitching, because I felt some pain. I think the injection was subsiding."

\section{Recovery}

MC clients offered few spontaneous comments about the immediate post-surgical recovery period, and no direct questions or probes had been prepared to explore this part of the MC process. Some clients said that pain peaked immediately following the surgery, such as a 16-yearold from Litsemba Letfu who said, "It was a bit painful after the surgery, but the pain subsided when I was at the recovery room." Other clients focused more on experiences of pain after they got home, or when they subsequently experienced involuntary erections. For example, a 17-yearold from FLAS said the surgery had not been painful but "it becomes painful when you leave the clinic" and a 22-year-old from Litsemba Letfu said "it's painful when I get an erection at home." 
Two clients had specific complaints about the post-procedure recovery period. A 17-year-old from FLAS said, "In the recovery room they say there is water but sometimes you don't find the water, and when you don't find someone who works at the clinic in the recovery room, it means you don't get the water when they know it is very important." A 26-year-old from MSI expressed lack of satisfaction with the post-procedure care he received, saying "I was not happy with the service because I did not get the underwear that they were supposed to give me, but when I ask other people they told me they were given that underwear. When I left the clinic the wound was painful and when I got home it was even worse."

\section{Experience versus Expectation}

Many MC clients, reflecting on how they felt prior to the surgery, said they had been extremely fearful about the pain that they would experience, but that their fears had been worse than their actual experiences. The majority of clients expressed surprise that they had not experienced any pain during the surgical removal of the foreskin, particularly given the anxiety they had felt in anticipation of the surgery. A 20-year-old from FLAS said he would tell a friend that "it is not as painful as he would think...it is as simple as an ear piercing."

\section{HEALING}

On the day of the MC procedure, clients receive a short booklet (available online at: http:// www.popcouncil.org/projects/211_MaleCircumcisionPartnership.asp\#/Resources) summarizing key messages about wound care and healing. The booklet explains that clients should rest and limit physical activity for the first two days post-procedure and should keep the bandage in place for 48 hours. It also explains that for a few weeks after the operation, once the dressing has been removed, the penis should be washed gently each day, using soap and water on a soft cloth. Clients are instructed to wait for six weeks to resume sexual activity (intercourse and masturbation), when the wound will be fully healed. Last, clients are told that erections may cause pain for several days, passing urine can help ease the pain, and specific medicine for preventing erections is not advised. The booklet also reminds clients to return for follow-up visits at two and seven days post-procedure, and provides contact information to send an SMS (short message service) text message or to call 24 hours a day, seven days a week, if they encounter any problems. Table 8 indicates how often specific healing instructions were mentioned by clients. ${ }^{7}$

Clients described varying degrees of comprehension and implementation of the wound care instructions they had received at the clinic. Many clients emphasized that following wound care instructions would promote healing, which had motivated adherence to instructions. Adults appeared to have a better understanding of wound care instructions than adolescents. The majority of adults, compared to less than half of adolescents, mentioned the need to keep the penis facing upright. Almost half of the clients specified they were to use Sunlight soap.

\footnotetext{
7 The instruction to rest and restrict movement immediately following circumcision was excluded from the table. Although this instruction was acknowledged by some, more often the avoidance of vigorous activity was assumed, and rarely discussed directly or spontaneously by clients.
} 
Table 8. Frequency of healing and wound care instructions mentioned by adult and adolescent clients in SSIs, $n=30$

\begin{tabular}{l|c|c|c} 
& $\begin{array}{c}\text { Adults } \\
(\mathbf{n = 1 6})\end{array}$ & $\begin{array}{c}\text { Adolescents } \\
(\mathbf{n}=14)\end{array}$ & $\begin{array}{c}\text { Total } \\
(\mathbf{n}=\mathbf{3 0})\end{array}$ \\
Adverse events indications and contact instructions & 16 & 13 & 29 \\
Wash & 9 & 9 & 18 \\
No sex for 6 weeks & 13 & 5 & 18 \\
Face penis upwards & 11 & 6 & 17 \\
Use Sunlight soap & 8 & 5 & 13 \\
Use salt (or salt water) & 5 & 7 & 12 \\
Avoid getting wound/dressing wet (before 2-day review) & 2 & 3 & 5 \\
Drink water/frequent urination to avoid involuntary erection & 4 & 0 & 4 \\
\hline
\end{tabular}

Note: Participants could list more than one instruction.

Four adolescents (all from FLAS), however, claimed that their understanding of the instructions was explicitly not to use soap. And, although the majority of clients mentioned the importance of washing or keeping the wound clean, only five mentioned the importance of not getting the wound wet for the first 48 hours post-surgery. Some clients described being confused by the complexity of the wound care instructions, whether or not to use soap or to wash the wound at all. A 23-year-old from Litsemba Letfu said, "Taking care of the wound is not easy, especially when you have to wash up. If you are used to using the shower, it then becomes difficult now that you are circumcised." Although the clinic instructions do not mention the use of salt or salt water for post-surgical care, half of the adolescents and five adults reported that they had been instructed to use salt. ${ }^{8}$ A 17-year-old from FLAS said, "I was not supposed to use soap but should use warm salty water. The salt helps to keep the wound dry.... That soap may have effects on the wound and you find that problems develop."

\section{Preparation for Healing}

Many clients expressed satisfaction with clear counseling that had addressed their main concerns about the healing period: predominantly, how much pain to expect during healing, how long the wound would take to heal, and what they could do to promote fast healing. For example, a 26-year-old from Litsemba Letfu said, "Yes, I got clear information [about healing], for the counselor told me that if I am going to follow the advices, the wound will not give me any problems...the counselor did explain everything that I wanted to know" and a 32-year-old from FLAS said the instructions he had received were clear because "what I was told was exactly what I experienced."

A few clients, however, felt that counseling had not prepared them for healing and wound care. A 20-year-old from FLAS said, "I wanted to know how to wipe my penis...to keep it clean," but the counselor "never said much, but just told me to take my medication."

\footnotetext{
${ }^{8}$ Because so many clients mentioned the instruction to use salt water, the PC research team followed up with clinical staff at PSI to find out whether salt water is ever recommended to clients. The PC team was informed that clients are sometimes advised to soak the wound in a "sitz bath" (salt water bath) if an infection is suspected; however, salt water is not routinely recommended.
} 


\section{Post-procedure Abstinence}

The instruction to avoid sexual activity for six weeks following $\mathrm{MC}$ was mentioned by almost all adults, but only five adolescents, presumably because the adolescents had all reported that they had not yet started having sex. Adults were generally primed to expect the external appearance of wound healing to occur before six weeks, but knew that they had to wait longer for internal healing. For example, a 23-year-old from Litsemba Letfu said, "You should wait for a period of six weeks before you start having sex again because by then the wound would have been completely healed. You should wait this long because sometimes the wound might look healed from the outside whereas it's not healed in the inside."

One adult discussed his perceptions of the six-week abstinence period and strategies for getting through it. He reported that although six weeks seemed like a long time to wait for sex, he hoped that open communication with his partner would be helpful.

Adolescents did not seem to have as clear an understanding as adults of the six-week postprocedure abstinence period. A 16-year-old from Litsemba Letfu said he was told that it was all right to have sex and start masturbating again "when the wound has completely healed...about eight weeks." A 17-year-old from FLAS said, "You only have sex when you have a wife...she [counselor] also said that you can have sex after six weeks."

\section{Care during the Healing Process}

Clients talked about the strategies that they had employed to ease discomfort during the healing period and expressed doubts about whether the use of antiseptics, painkillers or other "concoctions" was appropriate. A 22-year-old from Litsemba Letfu said, "I try to wash myself with soap. They told me not to apply any medication on my wound and mustn't drink any concoction and I've [been] trying to do just that."

Most adults said they were caring for the wound on their own, although one indicated that his wife had been assisting him. Most adults said they had not received instructions or support from anyone outside the clinic during the healing process, although a few men said they had received advice from friends. Some found this advice helpful, including a 21-year-old from FLAS who said his friend "told me not to walk long distances, and that really helped me." Other clients had been given advice that they mistrusted. A 22-year-old from Litsemba Letfu said, "There are some guys who told me of some concoctions that supposedly help the wound heal faster, but I didn't take that advice because I thought of the worst, in case my body responds negatively to that thing."

Many adolescents, on the other hand, reported the involvement of close family members, predominantly in terms of offering advice and suggestions for wound care. Some adolescents reported that family members had received specific instructions at the clinic, as explained by a 15-year-old from Litsemba Letfu who said, "My father did get it [instructions] from the clinic before, because he has been caring for my brothers, as well."

\section{Experience versus Expectation}

When asked how the healing process had compared to their expectations, the majority of clients (12 adults, 12 adolescents) said the healing process had been easier than they had expected, either because healing was quicker or less painful. A 21-year-old from FLAS said, "It has been easy for 
me, as I thought it would take about 3 months for me to heal up.... it was way quicker than I had anticipated." He further explained that "the pain was there but not that much...I can walk properly and even run. I can easily wash it without any hassles."

Some clients (three adults, five adolescents) reported that particular aspects of healing were different from what they had expected, such as being more painful or taking longer to show signs of healing. Although some clients reported satisfaction witnessing the progress of the healing wound, other clients were dismayed at unexpected surprises during the healing process for which they had felt ill-prepared, including bleeding, passing blood during or after urination, pain during involuntary erections, swelling, and feeling itchy. A 16-year-old from Litsemba Letfu said, "I wasn't told everything because when I was home I started bleeding and I didn't know why so I had to come back to the clinic. She should have told me that I could expect to bleed." Only a few clients mentioned the instruction to drink water to promote frequent urination and thus avoid the pain associated with involuntary erections.

\section{Adverse Events: Hypothetical and Actual}

Virtually all clients were familiar with the indications of an adverse event (AE) and the procedures for contacting clinic staff in the event of experiencing problems post-MC. Adults were well aware of signs that would indicate the wound was not healing well (including prolonged swelling, bleeding), and they reported feeling confident about contacting clinic staff if they were to experience any problems. Many clients knew the clinic contact details and appreciated knowing that they could "buzz" (send a short messages service-SMS) to be called back by clinic staff. A 23-year-old from Litsemba Letfu said, "They gave me a card that had their contact details and they told me that I should buzz that number and they would call me back if something was wrong." Another 23-year-old from Litsemba Letfu explained that "after the procedure, the penis does swell, but it has to last not more than 4 days. If it continued for more number of days, I was going to come back at the clinic." When asked whom he would contact he said, "I was going to call the emergency number they gave to me."

Adolescents were also aware of what constituted an AE, but described barriers to accessing followup care. Some of the younger adolescents reported that they would have to ask for permission or approval from a parent/guardian before seeking care, and would also have to seek help for transportation (especially money) to the clinic. For example, a 13-year-old from Litsemba Letfu explained that if he had any problems, "I was going to call the clinic...they gave me their numbers.... I was going to tell my mother before I call...my mother has to be there for me in difficult times."

Although a few clients seemed surprised by post-surgical outcomes, such as passing blood when urinating, only two of the 30 clients seemed to have experienced an AE. One client mentioned his experience of pain and bleeding that seemed out of the ordinary to him, but that did not seem to have been considered an $\mathrm{AE}$ by the clinic:

When I left the clinic the wound was painful and when I got home it was even worse. The bandage came off at night and I bled, the pain was unbearable such that I ended up taking four pills at a time when I supposed to take two. When I came back to the clinic the following day to tell them what had happened, they just told me they were not seeing any problem. When I told them the bandage did not come out the right way, they just did not care.

Adult, Aged 26, MSI 
Another client reported an experience that did seem to have been classified as an AE by the clinic staff:

\author{
Interviewer: Did you come at the clinic for the 2 nd- and 7 th-day reviews? \\ Participant: Yes I did. \\ Interviewer: What happened on the 2nd-day review? \\ Participant: They removed the bandage and varnished [put some ointment on] my \\ penis with some medication. \\ Interviewer: What happened on the 7th-day review? \\ Participant: They inspect[ed] the wound and [I] told them that blood comes out of \\ my penis after urinating, and I have been advised to go to hospital.
}

Adult, Aged 27, Litsemba Letfu

\title{
Post-Surgical Follow-up Visits
}

Clients reported that they had found the follow-up visits two and seven days post-surgery to be helpful, especially to receive advice and encouragement from clinic staff, to have the bandage removed and the wound cleaned, and to be reassured that healing was progressing well. Some clients were reportedly given pain medication for home use, but others were disappointed not to receive more pain medication at follow-up visits. A 17-year-old from FLAS said, "I showed my wound to the doctor so that he sees if everything is going well. You then explain what is happening and he gives you tablets if you don't have, but still need them." On the other hand, a 23-year-old from Litsemba Letfu said, "They just undo the bandage and they clean the wound; they don't give you anything for the pain you feel when they are removing the bandage."

\section{CLIENT INPUT ON SERVICE DELIVERY}

Almost all clients (14 adults, 13 adolescents) reported being satisfied with the MC services they received. A 21-year-old from Litsemba Letfu had specific praise for how well-prepared he had been for the healing process, explaining that "they put everything in a timeframe like two days, seven days; this shows that they gave themselves time to pre-test this thing."

Many clients talked about being treated well, and compared their experiences at MC sites with other health services they had received in the past. A 23-year-old from Litsemba Letfu said, "I think they are doing OK because the service is not like that you get in the government clinics... There is nothing I can add, because the service is very professional." A 17-year-old from FLAS said, "It is not like in hospitals where they can even shout at a patient. Here, they take care of their clients." A 22-year-old client, however, who was ultimately happy with the MC services he received at Litsemba Letfu, complained about FLAS saying, "I went to FLAS Manzini and we were not treated well. Hence, we went to another clinic. So, here [Litsemba Letfu] they are doing a very good job."

About half of the clients (eight adults, five adolescents), most of whom had been generally satisfied with their experiences, offered recommendations for improving specific aspects of MC service delivery when asked by the interviewers. 


\section{Outreach}

Several clients recommended expanding outreach, primarily at schools, because they consider $\mathrm{MC}$ to be such an important HIV prevention strategy. One adolescent recommended offering promotional T-shirts to encourage people to come for $\mathrm{MC}$, and several adults and adolescents mentioned the importance of clinic outreach in communities, and not relying solely on the media to get information to people.

Several clients mentioned barriers that had led them to delay accessing services and recommended that it would help people to know that MC services are free of charge and that, in some cases, transport is provided.

When circumcision was first introduced, we were together with my friends. We heard them talking about it, and we decided that it will be wise if we can go for the procedure... the fact that it was expensive costs us such that we didn't go, because we do not have money, since we are not employed. Recently, I learn [ed] from the radio that MC services are being provided here at Litsemba Letfu clinic for free...

Adult, aged 26, Litsemba Letfu

The best thing here is the transport, when they take you from home and take you back, because some people may not be able to walk after MC...If a person uses public transport, it may be a problem, because they may have to walk for long distances to get home and that may cause problems.

Adolescent, aged 17, FLAS

Finally, a 15-year-old from Litsemba Letfu said, "I would encourage them to consider neonatal $\mathrm{MC}$, because a child can stand pain better than an adult."

\section{Clinic Capacity}

Several clients discussed the need to increase capacity, either physical or human, at existing clinics, or to build new sites to make it easier for more people to access MC services. A 15-yearold from Litsemba Letfu recommended enlarging the reception area because there had not been enough room, so some clients had to wait outside. Several clients mentioned the need for more doctors to reduce waiting time. One client also mentioned that it would be helpful to segregate clients coming for post-operative follow-up visits from those who were waiting to be circumcised, because hearing the clients who were in the process of healing could frighten those who were not yet circumcised.

\section{Counseling}

Several clients had suggestions for strengthening the counseling process. An adult who had opted out of CT emphasized the importance of ensuring that clients have the opportunity to meet with a counselor one-on-one, even if they do not want to be tested for HIV. A few clients felt there should be a better explanation about why it is important to be tested for HIV before MC. Another adult felt that counselors should provide more information about what to expect during the healing period, and an adolescent said parents should also receive counseling to help their children with wound care at home. 


\section{Anesthesia}

Several clients recommended not showing the injections to the clients before surgery as that would make them more fearful. Others suggested replacing the injections with pills. Others requested fewer, stronger, longer-lasting injections, instead of the multiple injections they had received. A 27-year-old from Litsemba Letfu said, "If there is a way, the injection must be made to last for about three days in order for the penis not to be erect, for it is very painful when then the penis is erect with the stitches."

\section{Surgery and Recovery}

A few clients commented on ways to improve the surgical procedure or immediate recovery period. An adolescent from FLAS, who had noted that water was not available in the recovery room, said it was important for clinics to ensure all necessary supplies were on hand before conducting circumcisions. An adult from MSI had several complaints that suggested that he did not receive high-quality care. For example, he was concerned about a lack of infection precautions taken:

... there was something I did not like when I was in the surgery room. The doctor used cotton wool that had been used before... even though I don't know anything about [the] MC procedure, I know when something is right or not. I wonder why they did that, because at the clinic new tools should be used every time with a new client.

Adult, aged 26, MSI

Second, he had been disturbed to see a different provider in the operating theater than he had met in the assessment room and said, "The clients should be told that somebody else will be working on them and the doctor should not come to the surgery room with the mask on, so that the client sees his face."

Two adults from FLAS described problems with the stitches interfering with the underwear they had been given after the procedure. A 20-year-old said he would change "the way they stitch us, because it gets tangled up with the underwear," and a 32-year-old commented that "this underwear we are given by the clinic tend[s] to hook or tangle up with the stitches, which is very painful."

\section{Female Service Providers}

Two clients said that the most difficult part of the MC process for them had been their discomfort undressing in front of a female service provider, and the associated worries of involuntary erection. A 25-year-old from MSI said, "When I was supposed to be undressed, that was a problem because there was the female nurse on the side." However, despite his initial discomfort, he expressed an overall preference for female service providers, saying:

I want the female nurses to do the MC procedure because males are not very careful like the ladies would be. You should feel at home when they are doing this thing, the nurse that checked me was very careful unlike the male that I saw that day. It would be better if it were to be done by female doctors. 
A few clients recommended that clients should be given the opportunity to exercise the choice or at least be fully informed about who was going to conduct the procedure. A 22-year-old from Litsemba Letfu said, "I should be able to choose if I want to be attended by a female or male nurse, because some people are not comfortable when they will be attended by a certain gender."

\section{KEY FINDINGS}

Data from the quantitative and qualitative portion of the study were in agreement in terms of objective findings and subjective impressions. There was no evidence of pressure or coercion among any of the study participants, emphasized by the fact that all of the SSI participants said they made the decision to undergo MC voluntarily and that it had been their own choice. The majority of clients received the comprehensive counseling package (group and one-on-one MC counseling, plus CT), and nearly all clients had been tested for HIV before MC. Understanding of key concepts was excellent, although adults seemed to grasp key concepts better than adolescents, and the concept of "risk" was problematic among both adults and adolescents.

\section{Decisionmaking Process}

- Clients learn about MC primarily from the media, school, and outreach campaignsmost adults heard about MC through mass media or clinic IPC agents, whereas most adolescents learned about MC at school (primarily during back-to-school campaigns) or from family members.

- Key motivating factor is disease prevention — clients sought MC primarily for disease prevention (although HIV was not always mentioned specifically), and for improved hygiene or treatment of pre-existing medical conditions.

- Adults more comfortable with decision than adolescents - adults who participated in the quantitative comprehension assessment were more likely than adolescents to have reported feeling comfortable with the decision to undergo MC, or to feel they could change their minds. In SSIs conducted one week post-surgery, however, adults and adolescents talked about how it had been their own choice to be circumcised. The difference in responses between those interviewed before and after MC could have been due to the timing of the different interviews; although clients may have been comfortable with their decisions, they may not have been feeling "comfortable" just before the surgical procedure.

- Religious and logistic factors affected decisionmaking - for several clients, religious beliefs or views of specific religious leaders had delayed the decision to get circumcised. Other clients had delayed seeking services because they had to find the appropriate time to schedule the procedure without realizing that they would be given a medical note for their employer. Several adolescents acknowledged that they would have gone for MC sooner if they had known where to access services or had someone to take them.

\section{Counseling}

- Majority of clients received comprehensive counseling - the majority of clients received group and one-on-one MC counseling, and CT; most clients had CT, which is encouraging, because regular testing is an important HIV prevention strategy on its own. 
- Group and one-on-one MC counseling were complementary — some clients did not receive both group and one-on-one MC counseling, primarily because of client flow. Clients appreciated group counseling for the camaraderie and support of peers, and the opportunity to learn through questions and comments asked by other clients. One-on-one counseling was valued as a private and safe space to ask embarrassing questions about sexual activity and HIV risk.

- Clients wanted a clearer explanation of why HIV testing pre-MC is encouragedalthough most clients in the study had CT, some clients who participated in SSIs were unsure whether HIV testing had been mandatory, and why HIV testing is recommended before MC.

\section{Comprehension}

- Quantitative comprehension assessment indicates excellent overall understanding among clients preparing to undergo $M C$ - more than 90 percent of MC clients passed the ten-question true/false test (scored 80 percent or better), with no significant difference in pass rates by clinic type, location, or affiliation. Clients who heard about MC from friends versus any other source (e.g. clinic outreach, media, parents) were less than half as likely to pass; and clients who passed the literacy test versus those who did not were three times as likely to pass.

- Adolescents scored significantly lower than adults - significantly fewer adolescents (85.3 percent) than adults ( 95.5 percent) passed the comprehension test; mean scores and correct responses to most individual questions were also significantly lower for adolescents. SSIs support the quantitative findings; three adolescents said MC is 100 percent effective for HIV prevention, whereas all of the adults said MC is only partially protective. Adults were also better able to explain risks and benefits than adolescents.

- Clients receiving comprehensive counseling package performed best-95 percent of clients who received all three types of counseling passed the comprehension test; almost as many clients (93 percent) who had one-on-one MC counseling and CT (without group counseling) passed. Among clients who had group MC counseling and CT (no one-on-one $\mathrm{MC}$ counseling), only 61 percent of adolescents passed, underscoring the importance of one-on-one counseling for adolescents.

- Question about risks of MC surgery was most problematic - only 87 percent of clients said there are risks involved in the MC surgery, even though the question was phrased exactly as in the client information brochure: "risks of MC surgery include pain, swelling, or bleeding during or after surgery." Clients interviewed prior to MC may have considered potential risks to have been remote compared to the known benefits that led them to choose MC. It is also possible, however, as indicated by clients in SSIs, that risks were not emphasized as much as benefits in counseling.

- The term "risk" was difficult for clients to comprehend - most respondents in SSIs talked about the potential for bleeding, swelling, or lengthy healing, yet they did not always associate these with the word "risk." The term "risk" may have been confusing because it was used to convey two distinct (and somewhat contradictory) concepts; "risk" was used to indicate reduced chances of getting HIV post-MC, while simultaneously being used to describe potential consequences of the MC surgery itself.

- Clients were confused about "partial protection"-all adults and most adolescents interviewed one week post-MC said MC is not 100 percent protective against HIV; understanding of the actual level of protection varied. Three adolescents said MC is 100 percent protective against HIV, and many clients thought MC is fully protective against other STIs and cervical cancer. 
- Clients were unaware of increased HIV risk from resuming sex sooner than six weeks post-MC — all adults and most adolescents said it was necessary to abstain for six weeks after MC for complete wound healing; however, only two clients mentioned that initiating sex too soon could increase HIV risk.

- Clients were unsure whether MC protects female partner from HIV-most SSI participants said the effect of $\mathrm{MC}$ on reducing HIV risk for female partners had not been discussed in counseling. Many clients said they did not know whether $\mathrm{MC}$ was protective for women, whereas others incorrectly believed that if a man is circumcised his partner is automatically protected; only a few clients understood that MC protects women only indirectly.

\section{Informed Consent}

- Clients were circumcised voluntarily — there was no evidence that any clients were pressured or coerced into undergoing MC; however, clients who participated in SSIs did not seem to associate their voluntary choice with signing the IC form.

- Purpose of IC form was unclear - some clients perceived signing the IC form as a perfunctory step, necessary for proceeding with the MC surgery. Only one client clearly articulated that signing the consent form meant he was aware of risks and benefits and that he was voluntarily choosing to undergo MC. Some clients said they had not read the IC form before signing it, because they had not felt the need to do so, or because there had not been enough time before the procedure. Varying client perceptions of the IC form may be attributable to differences between the forms used by MC Partnership sites and FLAS; while the FLAS IC form includes a statement that the client will not sue the clinic (or service providers) if a complication occurs, PSI's form emphasized that the clinic will help clients if problems arise post-surgery.

- Consent procedures for minors were implemented inconsistently — procedures regarding the involvement of parents and guardians were not always implemented consistently; some adolescents seemed to have signed the consent form for themselves, despite being under 18 years of age. Regardless of who signed the consent forms, all of the adolescents participating in the SSIs had clearly chosen to undergo MC, and in all except one case, the adolescent had been the one to initiate the process.

\section{Procedure and Recovery}

- Clients were generally well-prepared for the MC procedure - most clients said they had been well-prepared for the MC procedure; however, seven adolescents said they had not been adequately prepared, despite not having asked questions during counseling. Adolescents may lack experience or may feel intimidated to ask questions, emphasizing the importance of alternative methods of providing information to adolescents and assessing their understanding of it.

- Pain injections were the most difficult part of $M C$ - most clients said the anesthesia injection was the most difficult aspect of the MC procedure. Many clients had been surprised to receive multiple injections. The majority of clients said only the first injection had been painful, but others said subsequent injections were also painful. A few clients said that the anesthesia had worn off too soon, so that they felt pain during suturing or right after the procedure. 
- Clients were surprised by lack of pain during removal of the foreskin-most clients had been surprised not to feel any pain during the surgery; many acknowledged that the fear of pain had been worse than the actual pain experienced.

\section{Healing}

- Most clients found bealing to be quicker and/or less painful than anticipated - most clients reported that the healing process went more smoothly than they had anticipated. A number of clients attributed their progress to carefully following the instructions for wound care provided by the clinic.

- Clients were aware of complications to watch for-clients had a good understanding of what constitutes an adverse event, and whom to call if they experienced any problems.

- Clients were confused about washing with salt water or soap - most clients understood the need to wash the wound daily, once the bandage was removed. A number of clients, however, indicated they were told to use salt or salt water to clean the wound instead of soap, and some were unclear about what they were supposed to do while the bandage was still in place.

\section{RECOMMENDATIONS}

Study results have already led to changes in IC procedures. Based on preliminary recommendations, the consent form used by FLAS clinics has been revised as follows:

1. The clause stating clients would not sue providers or clinics if complications arise was removed; and

2. A list of specific potential risks was added.

It is our hope that this extensive list of recommendations will provide useful information to support MC demand creation, strengthen the IC process, and improve service delivery.

\section{Expand Outreach Messages}

IC starts with community sensitization. As shown in this study, the majority of clients have already made the decision to undergo MC before coming to the clinic. Therefore, it is critical to include key messages in community outreach and education campaigns to ensure that clients make sound decisions based on accurate information. The better informed clients are before coming to the clinic, the more realistic their expectations will be, which has benefits for both clients and service providers.

\section{Clarify information about partial protection}

- Partial protection - the client information booklet states that MC does not provide 100 percent protection. However, because many clients believe they are at "low" rather than "reduced" risk after MC, it might be beneficial to revise messages to emphasize that if men have sex without condoms, their chances of getting HIV are still fairly high. 
- MC and women - although there is an information booklet specifically for women that explains the indirect effect of MC for women, it would be helpful to include this information in the client information brochures designed for males.

\section{Include practical information about service delivery}

- Pain - the client information booklet states "most patients don't have problems" (listing pain, bleeding, swelling, reaction to the medicine, and infection as typical problems), yet nearly all clients experience some pain before, during, or after the procedure. Clients would feel better prepared and informed if there was an acknowledgment that most clients will experience some pain during the injection(s) of anesthesia, after the procedure, and during healing.

- Length of recovery period - clients are aware that it takes six weeks for complete wound healing, but it would be useful for them to know in advance how long they will need to take off from work (or school), and whether a medical certificate can be provided for their employer or school.

- Clinic waiting time - the short duration of the MC procedure is emphasized, leading many clients to be surprised by the overall amount time spent at the clinic including registration, MC counseling, CT, pre-operative exam, surgery and recovery, and waiting time between steps. Clients would be better prepared if they knew in advance that they must spend several hours at the clinic when they go for MC.

- Service providers - build client confidence by emphasizing that all MC providers are trained professionals, who may be from Swaziland as well as other countries, and that many women, including professional counselors, nurses, and clinical officers, are involved in MC service delivery.

- Services are free of charge - actively publicize availability of free services.

- Transportation - if transport is provided, actively promote this benefit.

\section{Enhance Counseling Process}

\section{Standardize group plus one-on-one counseling package}

MC providers should ensure that clients receive both group and one-on-one counseling whenever possible. Clients benefit from having the opportunity to discuss $\mathrm{MC}$ with a group of peers for camaraderie and exchange of information, while also having the chance to talk privately with a counselor about their fears and questions. Strategies to consider include:

- Expand education efforts to provide more information to clients prior to the day of surgery - the amount of information distributed in the community about MC could be expanded, particularly through school outreach campaigns, so that clients receive the bulk of the information about MC before the day of the procedure. Clients may feel very nervous on the day of the surgery and may not recall any or all of the information they are given when they are feeling anxious. Expanding channels through which people get information before coming to the clinic will also allow clients the time to think about what they have heard, and then ask questions during one-on-one counseling before the surgery. It would also be beneficial to expand ways of providing information after MC—at follow-up visits or via SMS text messages - to emphasize some of the specific messages applicable to the healing process, such as increased risk of HIV transmission and lack of direct benefit for women. 
- Use a video for group education - a video could be shown in waiting rooms at fixed clinics or on laptops at outreach centers to standardize counseling and ensure that all clients get the same information. The use of a video for initial client education could also allow counselors to devote more of their time to one-on-one counseling. Video could be an especially useful tool for non-literate clients who are unable to read at all, or to read well enough to understand the relevant information.

\section{Improve counseling for adolescents}

- Neutral tone - group education sessions must address sex in a neutral, non-judgmental way to reflect the various stages of sexual activity among adolescents; adolescents who are not yet sexually active should not feel pressured to start having sex, and adolescents who have had prior experience should not feel embarrassed. Strategies for engendering comfort among adolescents include:

- Counseling adolescent clients separately from adult clients;

- Allowing adolescents to talk privately with a counselor, without their parent or guardian, where a counselor can tailor messages to their current situation and explain how MC will affect them in the future; and

- Having counselors acknowledge that some people may have had sex already and others may not, but that the information provided applies to everyone.

- Actively assess understanding - many adolescents do not ask questions during counseling - whether because they are fearful, are not used to asking questions of an authority figure, or do not have enough life experience to formulate questions. Therefore, it would be useful to develop a structured question-and-answer guide for use during counseling sessions with adolescents to ensure they understand the information being provided.

- Provide counseling for parents/guardians - add to existing efforts to involve parents by expanding the distribution of materials designed for parents and guardians, particularly regarding instructions for healing and wound care.

- Ensure one-on-one counseling for adolescents-even if adolescents do not undergo HIV testing, it is important that they have the opportunity to meet one-on-one with a counselor to enable counselors to better assess individual comprehension.

\section{Develop counseling materials and procedures for illiterate and semi-literate populations}

Literacy had a large impact on the likelihood of passing the comprehension test, so it would be beneficial to develop counseling materials (such as a video or booklet with more pictures/ illustrations) and procedures to ensure that messages are well understood by all clients, regardless of literacy level.

\section{Ensure understanding of "partial protection" for HIV and other STIs}

- Emphasize route of transmission once foreskin has been removed-many clients seem to believe that once the foreskin has been removed, they will be "clean" and there will be nowhere for diseases to "hide." Therefore, it is important to emphasize that HIV and other STIs are transmitted through blood and vaginal secretions, and that even without the foreskin, males are at risk of transmitting and getting diseases if they do not use condoms correctly and consistently. It is also important to ensure that clients understand that $\mathrm{MC}$ is not 100 percent effective in preventing other STIs or cervical cancer. 
- Stress that MC's protective effect against cervical cancer is only partial-messages should be refined so that clients understand that their partners will be less likely to get cervical cancer, but that $\mathrm{MC}$ does not completely eliminate the chances that female partners will get cervical cancer.

\section{Highlight the lack of protective effect against HIV for women}

The majority of clients interviewed were unaware of or unsure about the protection against HIV for female partners; few understood that MC protects partners only indirectly. Clients need to be informed that having sex before being fully healed can put their partners (and themselves) at increased risk for HIV infection. Strategies for conveying this message include:

Adding information on lack of protective effect on women to client booklet;

- Ensuring sufficient discussion about lack of protection during group and one-on-one counseling; and

- Emphasizing the importance of HIV testing before MC, because partners of HIV-positive men are at increased risk of HIV if men who are circumcised resume sex before six weeks.

\section{Distinguish between "risks" of MC surgery and "reduced risk" of HIVISTI}

Clients' comprehension of risk is critical to both the decisionmaking process prior to MC surgery and to successfully staying HIV negative after surgery. While "risk" is a complex concept to communicate to clients during the IC process, it is particularly difficult in the context of MC, where the term "risk" is used to describe potential negative consequences of the MC surgical procedure, as well as the positive benefit of reducing chances of contracting diseases.

- Explore use of different words or expressions to describe surgical risks vs. risk of HIVfor example, it might be clearer to people if "chance" or "possibility" was used in relation to lowered chances of getting HIV, and "risk" was used in the context of the surgical procedure.

- Use analogies to help clients understand the concept of probability — consider locally relevant analogies to explain the concept of "risk" or "probability," such as poker or lotto.

\section{Prepare clients for the likelihood of experiencing pain during procedure, recovery, and healing}

Honest and open discussion of the level and duration of pain that can reasonably be expected during and after $\mathrm{MC}$ will help to manage client expectations. Although counseling should continue to stress the diversity of possible client experiences, it is important for counselors to acknowledge that some clients will experience pain during the surgery, so that those who do experience high levels of pain do not lose their confidence in the MC providers and continue to trust the MC clinic staff for follow-up care.

- Acknowledge clients' fears as risks - many clients articulate fears about the MC procedure or healing process, but do not equate them with risks of the procedure. Counseling can help individual clients deal with their fears and acknowledge the likelihood of specific risks.

- Prepare clients better for anesthesia - it is important to give clients a realistic picture of what to expect, including:

- They will be awake during the procedure, and the pain medication will be administered via one or more injections at the base of the penis;

- It is likely that more than one injection will be required to numb the penis; 
- The first injection may be very painful; and

- Once the anesthesia takes effect, clients are unlikely to experience pain during the procedure.

- Expand discussion of pain during healing — counselors should describe the gradual reduction of pain during the healing process. Clients who knew what to expect at each stage (immediate recovery, two days after MC, one week post-MC, etc.) were better able to manage their experiences.

- Spell out wound care steps more clearly — it would be helpful for clients to have a guide to the step-by-step healing process instead of the more general information given to clients currently. Post-operative information should clearly indicate the instructions for each stage, with illustrations, as appropriate. Guidelines for washing with soap or salt water should be uniformly instituted across all sites, whether they are part of the MC Partnership or not, as inconsistencies in the community can lead to a lack of confidence in MC services.

- Stress the increased HIV risk from resumption of sex too soon-counselors should inform clients that the wound edges are raw for six weeks after surgery and that, in addition to disturbing the wound, delaying healing, or potentially causing infection, HIV risk is increased during the immediate post-healing period-for men if a female partner is infected with HIV; and for female partners if men are infected with HIV. It might also be useful to show clients pictures of what infection can look like so that they have an appreciation of the potential consequences of engaging in sex too soon.

- Clarify during counseling that the clinic provides support for any and all adverse events - counselors should make sure clients understand that they should return to the clinic if they suspect that there is any problem whatsoever (even if they sign a legal release from liability). The discussion of returning to the clinic for assistance should be integrated into provision of $\mathrm{AE}$ instructions (i.e. it should be mentioned by counselors and appear in printed instructions with $\mathrm{AE}$ contact details).

\section{Improve Aspects of the Informed Consent Process}

- Reinforce the meaning of signing the consent form - service providers should ensure that clients understand that signing the consent form means they have been given information about the procedure, have had all of their questions answered, understand the risks and benefits, and are indicating that they are choosing to undergo MC voluntarily. Clients should be reassured that no services will be denied and that continued services are not contingent upon MC service acceptance.

- Provide sufficient time for clients to read the IC form (or have it read to them) before they are asked sign it.

- Ensure that clients know they have recourse for $A E$ - - providers should ensure that clients understand that signing the IC form does not mean they cannot seek care and support if they experience AEs post-MC.

- Add language about increased HIV risk from resuming sex too soon to the informed consent form.

- Publicize consent regulations/requirements for minors during outreach - to ensure consistent (and legally appropriate) implementation of adolescent consent, it may be necessary to review and standardize consent/assent procedures for adolescents (starting with community outreach/sensitization), and to ensure that these protocols are appropriately communicated to adolescent clients and their accompanying parents/guardian.

- Consider adding information about lack of protection for female partners to IC forms. 


\section{APPENDIX A. STUDY OBJECTIVES, RESEARCH QUESTIONS, AND METHODS}

\begin{tabular}{|c|c|c|c|c|c|}
\hline \multirow[t]{3}{*}{ Objectives } & \multirow[t]{3}{*}{ Research questions } & \multicolumn{4}{|c|}{ Methods } \\
\hline & & \multicolumn{2}{|c|}{$\begin{array}{l}\text { Quantitative: } \\
\text { comprehension test }\end{array}$} & \multicolumn{2}{|c|}{$\begin{array}{l}\text { Qualitative: } \\
\text { SSIs }\end{array}$} \\
\hline & & Adults & Adolescents & Adults & Adolescents \\
\hline \multirow{6}{*}{$\begin{array}{l}\text { Decisionmaking } \\
\text { and informed } \\
\text { consent }\end{array}$} & $\begin{array}{l}\text { Why do adults choose to } \\
\text { undergo MC? }\end{array}$ & & & $\checkmark$ & \\
\hline & $\begin{array}{l}\text { How do adult males perceive } \\
\text { signing the MC form? }\end{array}$ & & & $\checkmark$ & \\
\hline & $\begin{array}{l}\text { How is the decision made for } \\
\text { adolescents to undergo MC? }\end{array}$ & & & & $\checkmark$ \\
\hline & $\begin{array}{l}\text { To what extent are adolescents } \\
\text { involved in the decision to } \\
\text { undergo MC? To what extent } \\
\text { are their parents/guardians } \\
\text { involved? }\end{array}$ & & & & $\checkmark$ \\
\hline & $\begin{array}{l}\text { Who signed the consent form } \\
\text { for the adolescents? }\end{array}$ & & $\checkmark$ & & $\checkmark$ \\
\hline & $\begin{array}{l}\text { What is the adolescent's } \\
\text { perspective on consent/assent? }\end{array}$ & & & & $\checkmark$ \\
\hline \multirow[t]{7}{*}{ Comprehension } & $\begin{array}{l}\text { Are at least } 90 \% \text { of } \mathrm{MC} \\
\text { clients able to score } 80 \% \text { on a } \\
\text { quantitative true/false test? }\end{array}$ & $\checkmark$ & $\checkmark$ & & \\
\hline & $\begin{array}{l}\text { Are scores significantly different } \\
\text { between adults/adolescents? }\end{array}$ & $\checkmark$ & $\checkmark$ & & \\
\hline & $\begin{array}{l}\text { Are scores significantly different } \\
\text { between fixed/outreach clinics? }\end{array}$ & $\checkmark$ & $\checkmark$ & & \\
\hline & $\begin{array}{l}\text { Are scores significantly different } \\
\text { between clients attending MC } \\
\text { Partnership sites vs. non- } \\
\text { partnership sites? }\end{array}$ & $\checkmark$ & $\checkmark$ & & \\
\hline & $\begin{array}{l}\text { Are scores significantly different } \\
\text { between clients attending rural } \\
\text { vs. urban sites? }\end{array}$ & $\checkmark$ & $\checkmark$ & & \\
\hline & $\begin{array}{l}\text { How well do MC clients } \\
\text { understand key concepts in the } \\
\text { MC IC process? }\end{array}$ & $\checkmark$ & $\checkmark$ & $\checkmark$ & $\checkmark$ \\
\hline & $\begin{array}{l}\text { Do clients understand } \\
\text { instructions for healing? (Wound } \\
\text { care, abstinence) }\end{array}$ & $\checkmark$ & $\checkmark$ & $\checkmark$ & $\checkmark$ \\
\hline \multirow[t]{2}{*}{$\begin{array}{l}\text { Expectations/ } \\
\text { satisfaction }\end{array}$} & $\begin{array}{l}\text { How satisfied are clients with } \\
\text { MC counseling? }\end{array}$ & & & $\checkmark$ & $\checkmark$ \\
\hline & $\begin{array}{l}\text { Do MC clients feel they were } \\
\text { prepared for procedure, } \\
\text { recovery, healing, based } \\
\text { on counseling? What } \\
\text { recommendations do clients } \\
\text { have for how they could have } \\
\text { been better prepared? }\end{array}$ & & & $\checkmark$ & $\checkmark$ \\
\hline
\end{tabular}




\section{APPENDIX B. RECRUITMENT TARGETS AND ENROLLMENT}

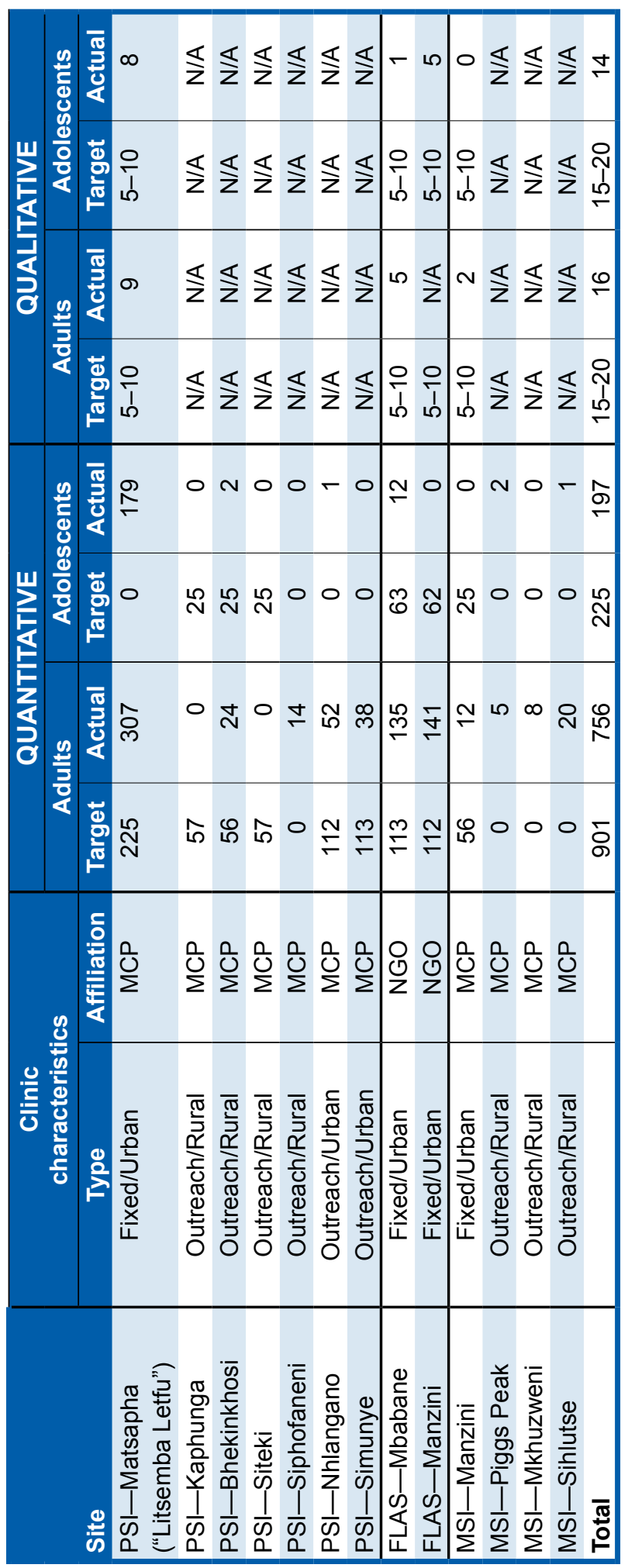




\section{APPENDIX C. CHARACTERISTICS OF CLIENTS WHO PARTICIPATED IN QUANTITATIVE COMPREHENSION ASSESSMENT}

Characteristics of clients who participated in the quantitative comprehension assessment, by age group and overall, $\mathrm{n}=953$

\begin{tabular}{|c|c|c|c|}
\hline Characteristic & $\begin{array}{c}\text { Adolescents } \\
n=197\end{array}$ & $\begin{array}{l}\text { Adults } \\
\mathrm{n}=756\end{array}$ & $\begin{array}{c}\text { All } \\
n=953\end{array}$ \\
\hline Age (mean, range) & $14.8(13-17)$ & $25.7(18-62)$ & $23.4(13-62)$ \\
\hline \multicolumn{4}{|l|}{ Nationality } \\
\hline SiSwati & $97.5 \%$ & $97.9 \%$ & $97.7 \%$ \\
\hline Mozambican/South African/Other & $2.5 \%$ & $2.3 \%$ & $2.3 \%$ \\
\hline \multicolumn{4}{|l|}{ Highest level education completed } \\
\hline None & $1.0 \%$ & $2.1 \%$ & $1.9 \%$ \\
\hline Some primary (grade $1-7$ ) & $58.9 \%$ & $14.2 \%$ & $23.4 \%$ \\
\hline Secondary (form 1-3) & $36.0 \%$ & $22.2 \%$ & $25.1 \%$ \\
\hline High school (form 4-5) & $4.1 \%$ & $41.1 \%$ & $33.5 \%$ \\
\hline $\begin{array}{l}\text { Higher (professional, certificate, } \\
\text { Masters, etc.) }\end{array}$ & $0.0 \%$ & $20.4 \%$ & $16.2 \%$ \\
\hline Passed numeracy test & $99.0 \%$ & $98.3 \%$ & $98.3 \%$ \\
\hline \multicolumn{4}{|l|}{ Literacy test results } \\
\hline Cannot read at all & $2.0 \%$ & $4.0 \%$ & $3.6 \%$ \\
\hline Able to read only part of sentence & $7.6 \%$ & $4.2 \%$ & $4.9 \%$ \\
\hline Able to read whole sentence & $90.4 \%$ & $91.7 \%$ & $91.5 \%$ \\
\hline Visually impaired & $0.0 \%$ & $0.1 \%$ & $0.1 \%$ \\
\hline \multicolumn{4}{|l|}{ Marital status } \\
\hline Never married & $100.0 \%$ & $77.5 \%$ & $82.2 \%$ \\
\hline Currently married or living together & $0.0 \%$ & $18.5 \%$ & $16.1 \%$ \\
\hline Has more than 1 wife & $0.0 \%$ & $1.7 \%$ & $1.4 \%$ \\
\hline Separated, divorced, widowed, other & $0.0 \%$ & $2.2 \%$ & $1.8 \%$ \\
\hline
\end{tabular}




\section{APPENDIX D. DECISIONMAKING PROCESS}

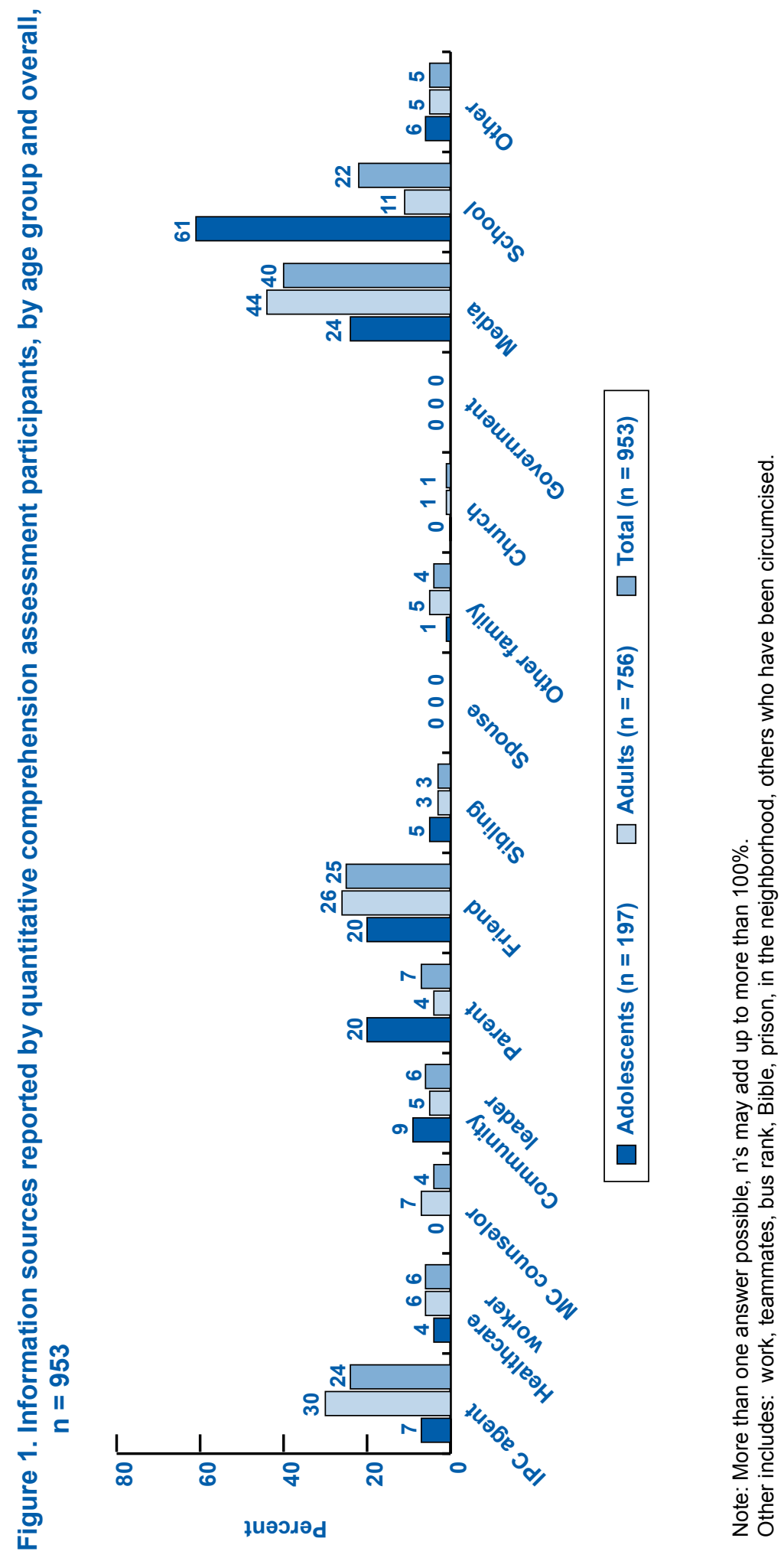


Figure 2. Decision comfort reported by quantitative comprehension assessment participants, by age group and overall, $n=953$

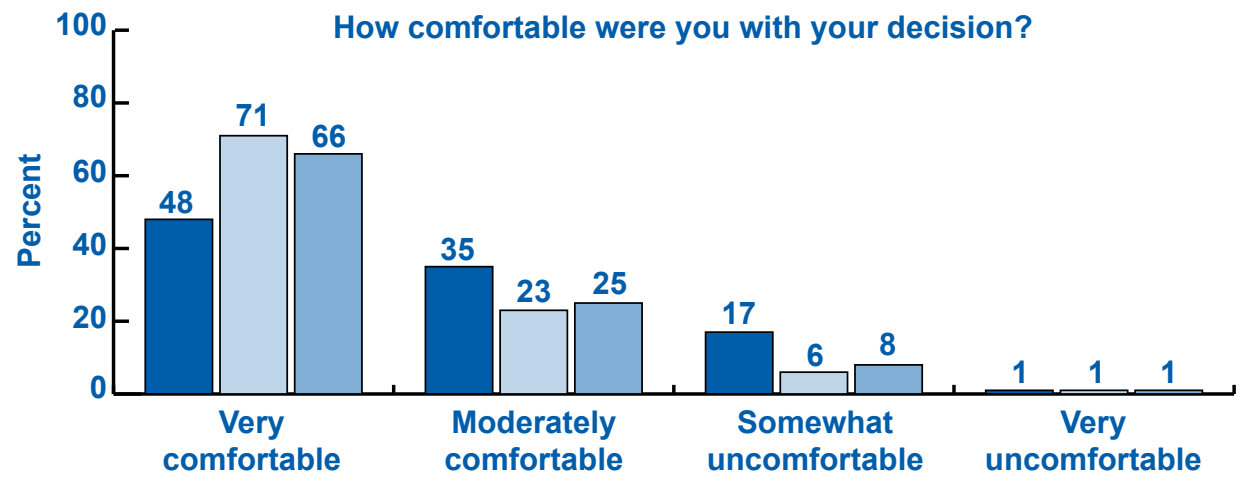

$\square$ Adolescents $(n=197) \quad \square$ Adults $(n=756) \quad \square$ Total $(n=953)$

Figure 3. Timing of decision reported by quantitative comprehension assessment participants, by age group and overall, $n=953$

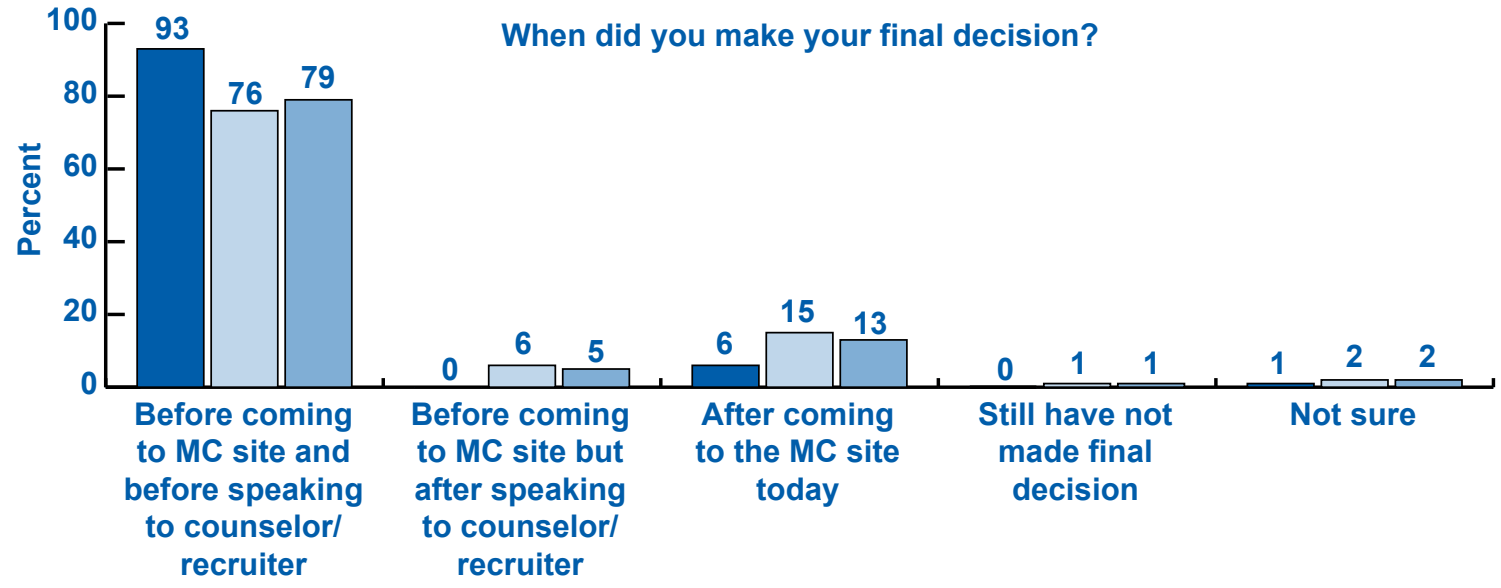

Adolescents $(n=197) \quad \square$ Adults $(n=756) \quad \square$ Total $(n=953)$

Figure 4. Percentage of quantitative comprehension assessment participants who felt they could change their minds about MC, by age group and overall, $n=953$

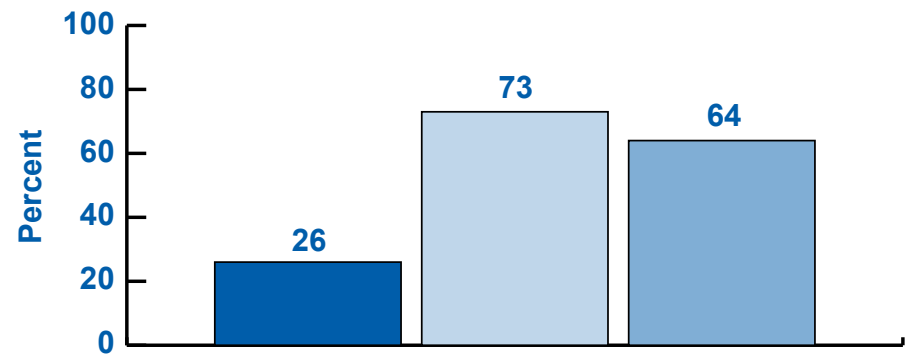

Adolescents $(\mathrm{n}=197) \quad \square$ Adults $(\mathrm{n}=756) \quad \square$ Total $(\mathrm{n}=953)$ 


\section{APPENDIX E. QUANTITATIVE COMPREHENSION ASSESSMENT: ADDITIONAL RESULTS}

Table 1. Comprehension assessment responses, pass rate, and mean scores, by question and age group, $\mathrm{n}=953$

\begin{tabular}{|c|c|c|c|c|}
\hline \multirow{2}{*}{$\begin{array}{l}\text { Question topic/ } \\
\text { label }\end{array}$} & \multicolumn{3}{|c|}{$\%$ giving correct response to question $(95 \% \mathrm{Cl})$} & \multirow{2}{*}{$\begin{array}{c}\text { Comparison } \\
\text { of adults } \\
\text { and } \\
\text { adolescents }^{\ddagger}\end{array}$} \\
\hline & $\begin{array}{l}\text { Adolescents } \\
\quad(n=197) \\
\%, \text { Cl, }^{\text {p-value }}{ }^{\dagger}\end{array}$ & $\begin{array}{c}\text { Adults } \\
(\mathrm{n}=756) \\
\%, \mathrm{Cl}, \mathrm{p} \text {-value } \\
\end{array}$ & $\begin{array}{c}\text { MC clients } \\
(n=953) \\
\%, \text { Cl, p-value }\end{array}$ & \\
\hline $\begin{array}{l}1 \text { Condoms } \\
\text { during sex }\end{array}$ & 88.8 (84.4-93.3) & $98.7(97.9-99.5)^{\star \star}$ & $96.6(95.5-97.8)^{* \star}$ & ** \\
\hline 2 Injection & $93.4(89.9-96.9)$ & $93.3(91.5-95.0)^{\star *}$ & $93.3(91.7-94.9)^{\star \star}$ & $\mathrm{n} / \mathrm{a}$ \\
\hline 3 Six weeks & $90.4(86.2-94.5)$ & $96.4(95.1-97.8)^{\star \star}$ & $95.2(93.8-96.5)^{\star \star}$ & ** \\
\hline 4 Risks & $87.3(82.6-92.0)$ & $86.8(84.4-89.2)^{\star *}$ & $86.9(84.7-89.0)^{\star \star}$ & $\mathrm{n} / \mathrm{a}$ \\
\hline 5 Wound healing & $94.4(91.2-97.7)^{\star *}$ & $97.8(96.7-98.8)^{\star \star}$ & $97.1(96.0-98.1)^{\star \star}$ & * \\
\hline 6 HIV negative & $84.8(79.7-89.8)^{\star}$ & $90.3(88.2-92.5)$ & $89.2(87.2-91.2)$ & * \\
\hline 7 Sexual partners & $92.4(88.6-96.1)$ & $96.6(95.3-97.9)^{\star \star}$ & $95.7(94.4-97.0)^{\star \star}$ & * \\
\hline 8 Penile cancer & $85.3(80.3-90.3)$ & $87.3(84.9-89.7)^{\star}$ & $86.9(84.7-89.0)^{\star \star}$ & $\mathrm{n} / \mathrm{a}$ \\
\hline 9 Female partner & $78.7(72.9-84.4)^{\star *}$ & $92.1(90.1-94.0)^{*}$ & $89.3(87.3-91.3)$ & $* *$ \\
\hline $10 \mathrm{STI}$ & $86.3(81.4-91.1)$ & $95.6(94.2-97.1)^{\star \star}$ & $93.7(92.2-95.2)^{\star *}$ & ** \\
\hline $\begin{array}{l}\text { Percent passing } \\
\text { test }\end{array}$ & $85.3(80.3-90.3)$ & $95.5(94.0-97.0)^{\star \star}$ & $93.4(91.8-95.0)^{* *}$ & ** \\
\hline $\begin{array}{l}\text { Mean score } \\
\text { (number of } \\
\text { questions correct) }\end{array}$ & $8.82(8.61-9.02)$ & $9.35(9.28-9.41)^{* \star}$ & $9.24(9.17-9.31)^{\star \star}$ & ** \\
\hline
\end{tabular}

Notes: $\mathrm{Cl}=$ confidence interval; t-test $\mathrm{p}$-values: ${ }^{*}<0.05 ;{ }^{* *}<0.01$; ${ }^{\dagger}$ One-sided t-test comparing percent passing to null hypothesis ( $90 \%$ passing); ${ }^{2} 2$-sided t-test comparing percent passing test among adults vs. adolescents

Figure 1. Comprehension assessment pass rates, by type of counseling received, by age group and overall, $n=953$

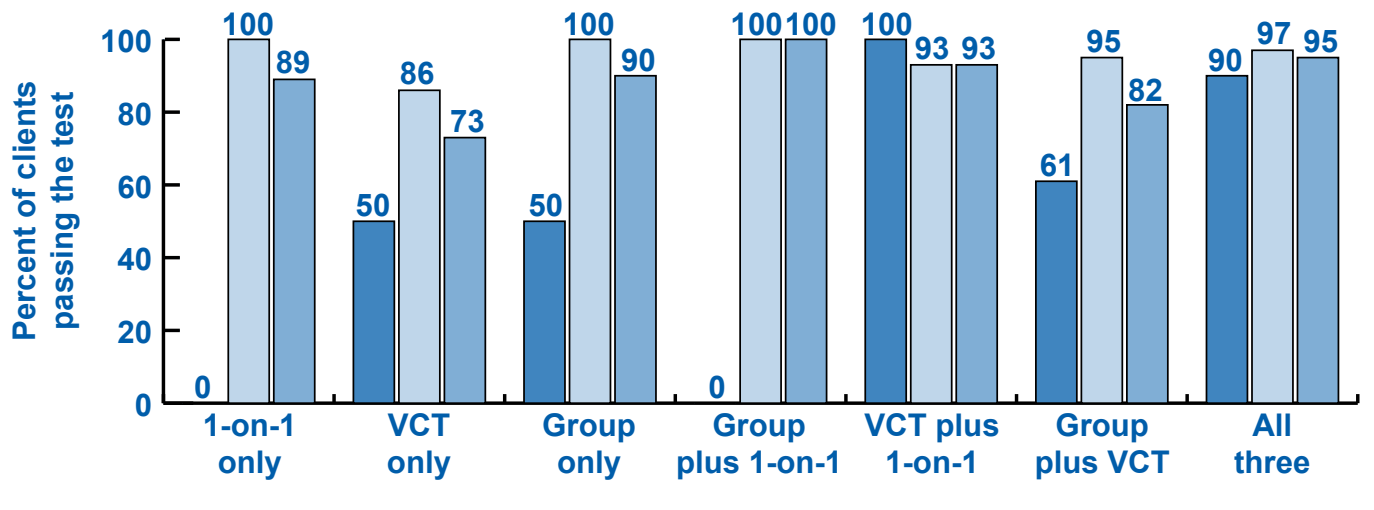

Type of counseling received

Adolescents $(n=197) \quad \square$ Adults $(n=756) \quad \square$ Total $(n=953)$ 
Table 2. Comprehension assessment responses, pass rates, and mean scores, by question and clinic type, $n=953$

\begin{tabular}{|c|c|c|c|}
\hline \multirow[t]{2}{*}{ Question } & \multicolumn{3}{|c|}{$\%$ overall getting question correct $(95 \% \mathrm{CI})$} \\
\hline & $\begin{array}{c}\text { Outreach }(\mathrm{n}=167) \\
\%, \mathrm{Cl}\end{array}$ & $\begin{array}{c}\text { Fixed }(n=786) \\
\%, \mathrm{Cl}\end{array}$ & $\begin{array}{c}\text { MC clients ( } \mathrm{n}=953) \\
\%, \mathrm{Cl}, \mathrm{p} \text {-value }\end{array}$ \\
\hline 1 Condoms during sex & 97.6 (95.3-99.9) & 96.4 (95.1-97.7) & 96.6 (95.5-97.8) \\
\hline 2 Injection & $94.0(90.4-97.6)$ & $93.1(91.4-94.9)$ & $93.3(91.7-94.9)$ \\
\hline 3 Six weeks & $95.2(91.9-98.5)$ & $95.2(93.7-96.7)$ & 95.2 (93.8-96.5) \\
\hline 4 Risks & $92.8(88.9-96.8)$ & $85.6(83.2-88.1)$ & $86.9(84.7-89.0)^{\star}$ \\
\hline 5 Wound healing & 95.8 (92.7-98.9) & $97.3(96.2-98.5)$ & $97.1(96.0-98.1)$ \\
\hline 6 HIV negative & $88.0(83.0-93.0)$ & $89.4(87.3-91.6)$ & $89.2(87.2-91.2)$ \\
\hline 7 Sexual partners & $92.8(88.9-96.8)$ & $96.3(95.0-97.6)$ & $95.7(94.4-97.0)^{*}$ \\
\hline 8 Penile cancer & $92.2(88.1-96.3)$ & 85.8 (83.3-88.2) & $86.9(84.7-89.0)^{*}$ \\
\hline 9 Female partner & $93.4(89.6-97.2)$ & $88.4(86.2-90.7)$ & $89.3(87.3-91.3)$ \\
\hline $10 \mathrm{STI}$ & $95.2(91.9-98.5)$ & $93.4(91.6-95.1)$ & $93.7(92.2-95.2)$ \\
\hline Percent passing test & $94.0(90.4-97.6)$ & $93.3(91.5-95.0)$ & $93.3(91.8-95.0)$ \\
\hline $\begin{array}{l}\text { Mean score (number of } \\
\text { questions correct) }\end{array}$ & $9.37(9.21-9.53)$ & $9.21(9.13-9.29)$ & $9.24(9.17-9.31)$ \\
\hline
\end{tabular}

Notes: $\mathrm{Cl}=$ confidence interval; t-test $\mathrm{p}$-values for comparison between outreach and fixed clinics: ${ }^{*}<0.05 ;{ }^{* *}<0.01$

Figure 2. Comprehension assessment pass rates and mean scores, by site, $n=953$

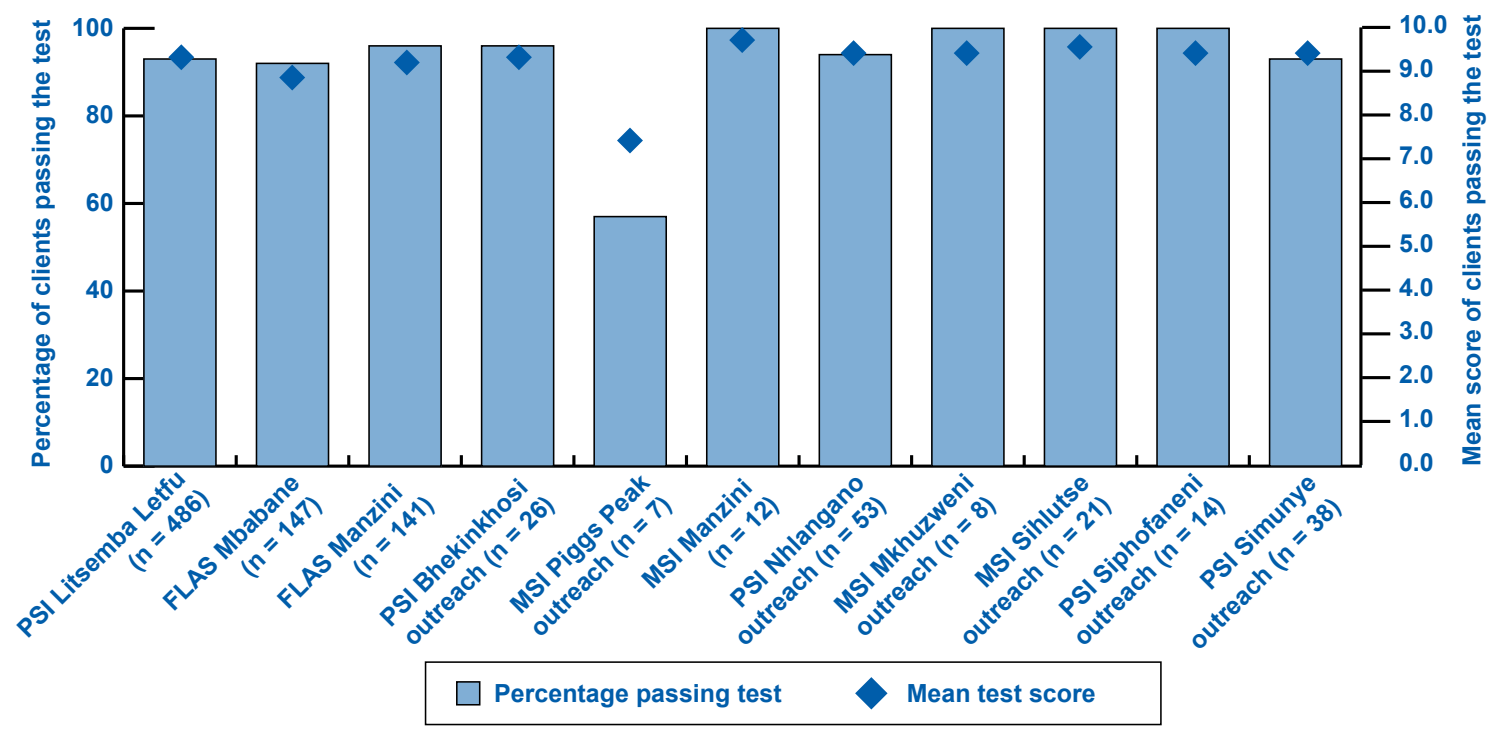


Table 3. Comprehension assessment responses, pass rates, and mean scores, by question and clinic affiliation, $\mathrm{n}=953$

\begin{tabular}{|c|c|c|c|}
\hline \multirow[t]{2}{*}{ Question } & \multicolumn{3}{|c|}{$\%$ overall getting question correct $(95 \% \mathrm{Cl})$} \\
\hline & $\begin{array}{c}\text { FLAS }(\mathrm{n}=288) \\
\%, \mathrm{Cl}\end{array}$ & $\begin{array}{c}\mathrm{MCP}(\mathrm{n}=665) \\
\%, \mathrm{Cl}\end{array}$ & $\begin{array}{c}\text { MC clients ( } \mathrm{n}=953 \text { ) } \\
\%, \mathrm{Cl}, \mathrm{p} \text {-value }\end{array}$ \\
\hline 1 Condoms during sex & $98.3(96.7-99.8)$ & $95.9(94.4-97.4)$ & $96.6(95.5-97.8)$ \\
\hline 2 Injection & $89.6(86.0-93.1)$ & $94.9(93.2-96.6)$ & $93.3(91.7-94.9)^{* *}$ \\
\hline 3 Six weeks & $96.9(94.9-98.9)$ & $94.4(92.7-96.2)$ & $95.2(93.8-96.5)$ \\
\hline 4 Risks & $75.0(70.0-80.0)$ & $92.0(90.0-94.1)$ & $86.9(84.7-89.0)^{\star \star}$ \\
\hline 5 Wound healing & $98.6(97.3-100.0)$ & $96.4(95.0-97.8)$ & $98.6(97.3-100)$ \\
\hline 6 HIV negative & $88.9(85.2-92.5)$ & $89.3(87.0-91.7)$ & $89.2(87.2-91.2)$ \\
\hline 7 Sexual partners & $97.2(95.3-99.1)$ & 95.0 (93.4-96.7) & $95.7(94.4-97.0)$ \\
\hline 8 Penile cancer & $79.2(74.4-83.9)$ & $90.2(88.0-92.5)$ & $86.9(84.7-89.0)^{\star \star}$ \\
\hline 9 Female partner & $89.2(85.6-92.8)$ & $89.3(87.0-91.7)$ & $89.3(87.3-91.3)$ \\
\hline $10 \mathrm{STI}$ & $93.8(90.9-96.6)$ & $93.7(91.8-95.5)$ & $93.7(92.2-95.2)$ \\
\hline Percent passing test & $94.1(91.4-96.8)$ & $93.1(91.1-95.0)$ & $93.4(91.8-95.0)$ \\
\hline $\begin{array}{l}\text { Mean score (number of } \\
\text { questions correct) }\end{array}$ & $9.07(8.95-9.18)$ & $9.31(9.23-9.40)$ & $9.24(9.17-9.31)^{\star \star}$ \\
\hline
\end{tabular}

Notes: $\mathrm{Cl}=$ confidence interval; t-test $\mathrm{p}$-values for comparison between MCP and FLAS clinics: ${ }^{*}<0.05 ;{ }^{* *}<0.01$

Table 4. Comprehension assessment responses, pass rates, and mean scores, by question and clinic location, $n=953$

\begin{tabular}{|c|c|c|c|}
\hline \multirow[t]{2}{*}{ Question } & \multicolumn{3}{|c|}{$\%$ overall getting question correct $(95 \% \mathrm{CI})$} \\
\hline & $\begin{array}{l}\text { Rural }(n=69) \\
\quad \%, \mathrm{Cl}\end{array}$ & $\begin{array}{c}\text { Urban }(\mathrm{n}=932) \\
\%, \mathrm{Cl}\end{array}$ & $\begin{array}{c}\text { MC clients ( } n=953) \\
\%, \mathrm{Cl}, \mathrm{p} \text {-value }\end{array}$ \\
\hline 1 Condoms during sex & $100.0(1.0-1.0)$ & $96.4(95.1-97.6)$ & $96.6(95.5-97.8)$ \\
\hline 2 Injection & $95.7(90.7-100.6)$ & $93.1(91.4-94.8)$ & $93.3(91.7-94.9)$ \\
\hline 3 Six weeks & $97.1(93.0-101.2)$ & $95.0(93.6-96.5)$ & $95.2(93.8-96.5)$ \\
\hline 4 Risks & $89.9(82.5-97.2)$ & $86.7(84.4-88.9)$ & $86.9(84.7-89.0)$ \\
\hline 5 Wound healing & $94.2(88.5-99.9)$ & $97.3(96.2-98.4)$ & $97.1(96.0-98.1)$ \\
\hline 6 HIV negative & $85.5(77.0-94.0)$ & $89.5(87.4-91.5)$ & $89.2(87.2-91.2)$ \\
\hline 7 Sexual partners & 92.8 (86.5-99.0) & $95.9(94.6-97.2)$ & 95.7 (94.4-97.0) \\
\hline 8 Penile cancer & $94.2(88.5-100)$ & $86.3(84.0-88.6)$ & $86.9(84.7-89.0)$ \\
\hline 9 Female partner & $95.7(90.7-100.6)$ & $88.8(86.7-90.9)$ & $89.3(87.3-91.3)$ \\
\hline $10 \mathrm{STI}$ & $98.6(95.7-101.4)$ & $93.3(91.7-95.0)$ & $93.7(92.2-95.2)$ \\
\hline Percent passing test & $97.1(93.0-101.2)$ & $93.1(91.4-94.8)$ & $93.4(91.8-95.0)$ \\
\hline $\begin{array}{l}\text { Mean score (number of } \\
\text { questions correct) }\end{array}$ & $9.43(9.26-9.61)$ & $9.22(9.15-9.3)$ & $9.24(9.17-9.31)$ \\
\hline
\end{tabular}

Note: $\mathrm{Cl}=$ confidence interval 
Table 5. Logistic regression modeling the odds of passing the comprehension test, $n=953$

\begin{tabular}{|l|c|c|c|c|}
\hline VARIABLE [reference group] & AOR & $95 \%$ CI & Std. Err. & $\mathbf{P}>|\mathbf{z}|$ \\
\hline $\begin{array}{l}\text { Predictors found to be statistically significant } \\
\text { (p < 0.05) }\end{array}$ & & & & \\
$\quad$ Age group [Adolescents (13-17)] & 3.45 & $1.35-8.77$ & 1.64 & 0.009 \\
$\quad$ Adult (18+) & 2.92 & $1.30-6.60$ & 1.21 & 0.010 \\
$\quad$ Able to read entire sentence [No]/Yes & 0.44 & $0.24-0.80$ & 0.14 & 0.007 \\
$\quad$ Heard about MC from friend [No]/Yes & & & & \\
Predictors not found to be statistically significant \\
(p > 0.05)
\end{tabular}

Notes: $\mathrm{AOR}=$ adjusted odds ratio; $\mathrm{Cl}=$ confidence interval 


\section{REFERENCES}

Auvert, B. et al. 2005. "Randomized, controlled intervention trial of male circumcision for reduction of HIV infection risk: The ANRS 1265 trial," PLoS Med 11: e298: 1112-1122.

Bailey, R. et al. 2007. "Male circumcision for HIV prevention in young men in Kisumu, Kenya: A randomised controlled trial,” Lancet 369: 643-656.

Bayer, R. 2000. "Ethical challenges of HIV vaccine trials in less developed nations: Conflict and consensus in the international arena," AIDS 14: 1051-1057.

Benatar, S. 2002. "Reflections and recommendations on research ethics in developing countries," Social Science and Medicine 54: 1131-1141.

Central Statistical Office (CSO) [Swaziland], and Macro International Inc. 2008. Swaziland Demographic and Health Survey 2006-07. Mbabane, Swaziland: Central Statistical Office and Macro International Inc.

de Zoysa, I., C. Elias, and M. Bentley. 1998. "Ethical challenges in efficacy trials of vaginal microbicides for HIV prevention," American Journal of Public Health 88: 571-575.

Fitzgerald, D., C. Marotte, and R. Verdier. Council for International Organizations of Medical Sciences (CIOMS). 2002. International Ethical Guidelines for Biomedical Research Involving Human Subjects. Geneva: WHO.

Gray, R. et al. 2007. "Male circumcision for HIV prevention in men in Rakai, Uganda: A randomised trial," Lancet 369: 657-666.

Kingdom of Swaziland. 2009. "The national multi-sectoral strategic framework for HIV and AIDS 2009-2014." Mbane, Swaziland.

Lavori, P.W. et al. 1999. "Improving informed consent in clinical trials: A duty to experiment," Controlled Clinical Trials 20: 187-193.

Ministry of Health [Swaziland]. 2009. "Policy on safe male circumcision for HIV prevention." Swaziland: Ministry of Health.

Molyneux, C.S., N. Peshu, and K. Marsh. 2004. "Understanding of informed consent in a low-income setting: Three case studies from the Kenyan coast," Social Science and Medicine 59: 2547-2559.

Schenk, K.D., and J. Williamson. 2005. Ethical Approaches to Gathering Information from Children and Adolescents in International Settings: Guidelines and Resources. Washington DC: Horizons/Population Council, Family Health International/Impact, United States Agency for International Development (USAID).

The Joint United Nations Programme on HIV/AIDS (UNAIDS). 2008. Safe, Voluntary, Informed Male Circumcision and Comprehensive HIV Prevention Programming: Guidance for Decision-Makers on Human Rights, Ethical and Legal Considerations. Geneva, Switzerland: UNAIDS.

United Nations High Commissioner for Human Rights (UNHCHR). 1989. Convention on the Rights of the Child. New York, NY. (http://www2.ohchr.org/english/law/crc.htm) Accessed 25 March 2011.

Wawer, M.J. et al. 2009. "Circumcision in HIV-infected men and its effect on HIV transmission to female partners in Rakai, Uganda: A randomised controlled trial," Lancet 374: 229-237.

Woodsong, C., and Q. Abdool Karim. 2004. "A model to enhance informed consent: Experiences from the HIV Prevention Trials Network," American Journal of Public Health 95: 412-419.

World Health Organization/The Joint United Nations Programme on HIV/AIDS (WHO/UNAIDS). 2007. New Data on Male Circumcision and HIV Prevention: Policy and Programme Implications. Conclusions and recommendations of the WHO/UNAIDS Technical Consultation, March 6-8, Montreux, Switzerland. 






\section{Population Council}

www.popcouncil.org

\section{Population Council}

One Dag Hammarskjold Plaza

New York, New York 10017

USA

Telephone: +1 2123390500

Facsimile: +1 2127556052

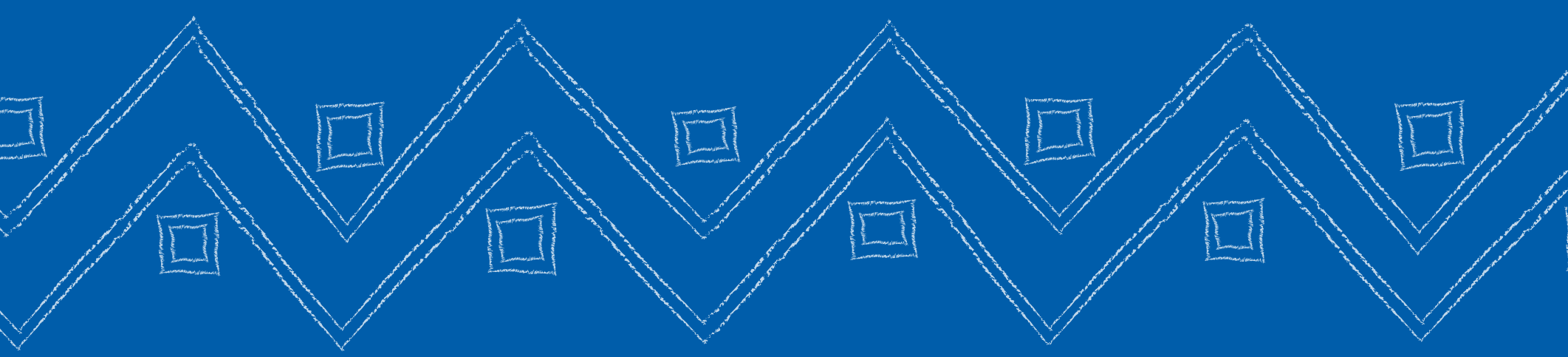

